\title{
Sistematización cronológica de la pintura rupestre esquemática en la provincia de Badajoz: Los abrigos de la Sierra de Magacela
}

\author{
Hipólito Collado Giraldo
}

\begin{abstract}
En los últimos años, bajo la dirección de Prof. Dr. Don Eduardo Ripoll Perelló, se están realizando dos tesis doctorales a cargo de Doña María Isabel Martínez Perelló y el que suscribe, cuya finalidad es la investigación, estudio, divulgación y puesta en valor de la pintura rupestre esquemática de la provincia de Badajoz. Fruto de estos trabajos ha sido el descubrimiento de más de un centenar de nuevos abrigos que no hacen sino confirmar a Badajoz y a Extremadura como uno de los enclaves fundamentales en el desarrollo del fenómeno esquemático peninsular ${ }^{1}$ (fig. 1).

Entre ellos los nuevos abrigos localizados en la Sierra de Magacela son una mínima parte del gran complejo esquemático extremeño; su importancia radica en las especiales características técnicas y estilísticas que reúnen, así como en el aceptable estado de conservación de las pinturas, lo que nos va a permitir observar de forma fácil una serie de singulares superposiciones de motivos y colores, que permiten establecer tres diferentes períodos cronológicos en la realización de las mismas.
\end{abstract}

\section{LOCALIZACIÓN}

Cerrando la inmensa planitud del valle de la Serena hacia el oeste, se levanta, soberbia, esta alineación cuarcítica de poco más de cuatro kilómetros de longitud, orientada NW-SE con una altura máxima de $562 \mathrm{~m}$.

\footnotetext{
1 Collado Giraldo H:: (en prensa), «La pintura rupestre esquemática en Badajoz: estado de la investigación», Revista de Estudios Extremeños, 1994.
} 


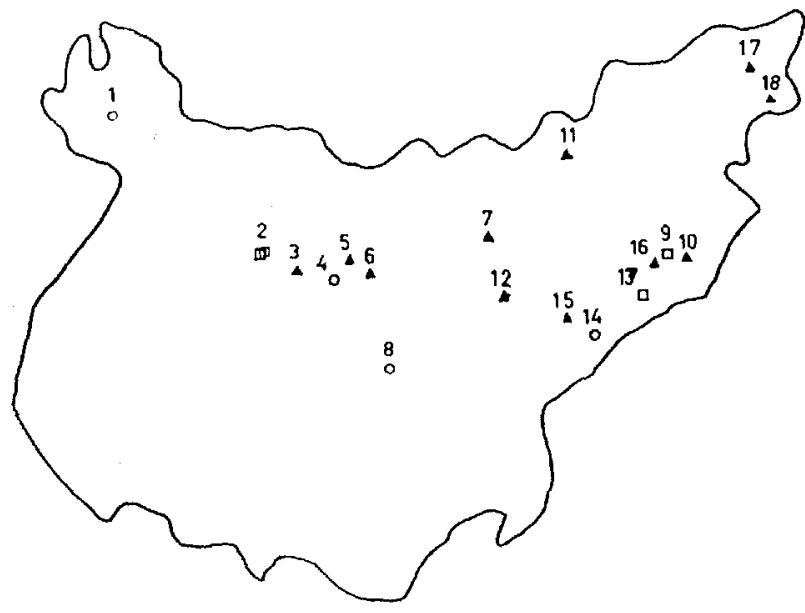

- Hasta 6 abrigos
- De 6 a 12

De 6 a 12
D Más de 12

Figura 1. Distribución de los abrigos con pintura rupestre esquemática en la provincia de Badajoz:

1. Alburquerque. 2. Arroyo de San Serván. 3. Torremegía. 4. Alange, 5. Zarza de Alange. 6. Oliva de Mérida. 7. Magacela. 8. Hornachos. 9. Peñalsordo. 10. Capilla. 11. Navalvillar de Pela. 12. Quintana de la Serena. 13. Cabeza del Buey. 14. Helechal. 15. Benquerencia de la Serena. 16. Zarza Capilla. 17. Helechosa. 18. Villarta de los Montes.

localizada en el cerro del Castillo. En sus laderas, no ha mucho cubiertas por alcornocales y jaras, se alzan espigados eucaliptos fruto de inconscientes repoblaciones que han empobrecido el suelo de tal manera que en él sólo arraigan escobas y esparragueras con algunas concesiones a la lavanda y el tomillo. Ello ha reducido enormemente la capacidad de explotación de estas tierras, actualmente entregadas a usos cinegéticos comunales y al pastoreo de ganado casi exclusivamente caprino (fig. 2).

\section{DESCRIPCIÓN DE LOS NUEVOS ABRIGOS DE LA SIERRA DE MAGACELA}

\section{Abrigo A}

El abrigo A se localiza en la vertiente Este de la sierra de Magacela, dentro del término municipal del mismo nombre, a una altura aproximada de $500 \mathrm{~m}$. y con una orientación SE-NW/SW-NE (hoja del S.G.E. 1/50.000, no 779, designación: 30STJ616098). 


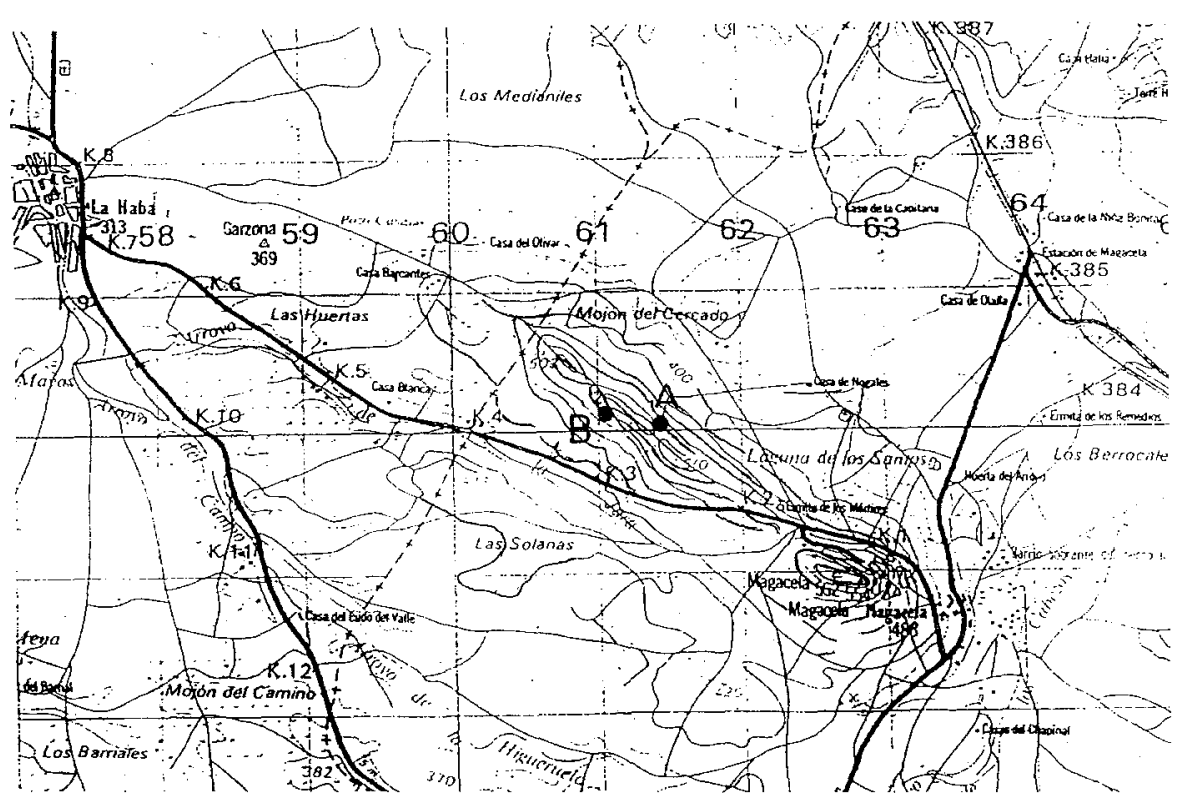

Figura 2. Localización de los abrigos de la Sierra de Magacela. Hoja del S.G.E. $1 / 50.000$, n. 979 (Villanueva de la Serena)

El acceso se realiza por la carretera que une las poblaciones de La Haba y Magacela. Aproximadamente a un kilómetro de Magacela (siempre viniendo desde La Haba) se toma a la izquierda una pista que se dirige al repetidor de T.V. hasta la altura del transformador que surte de energía eléctrica al mismo, desde donde se continúa a pie un centenar de metros por un sendero que corre paralelo a la línea de sierra desde el cual, tras desviarse a la derecha, se accede al abrigo después de cruzar a la umbría por el paso que se abre entre la elevación que sustenta el repetidor y la que le continúa en la línea de sierra.

Nos encontramos ante un impresionante yacimiento pictórico formado por dos enormes farallones cuarcíticos en escuadra, que llegan a superar los quince metros de altura en las cotas superiores. El frontal se orienta NW-SE, similar a la orientación general de la sierra de Magacela y alcanza una longitud aproximada de $25 \mathrm{~m}$. El segundo farallón, de menor altura, está orientado SW-NE y su longitud supera los $16 \mathrm{~m}$. El nivel de base del abrigo buza de forma pronunciada hacia el NE.

Para sistematizar de la forma más clara la descripción de las figuras, hemos dividido el lienzo rocoso en 19 grupos, siguiendo como criterio, en 


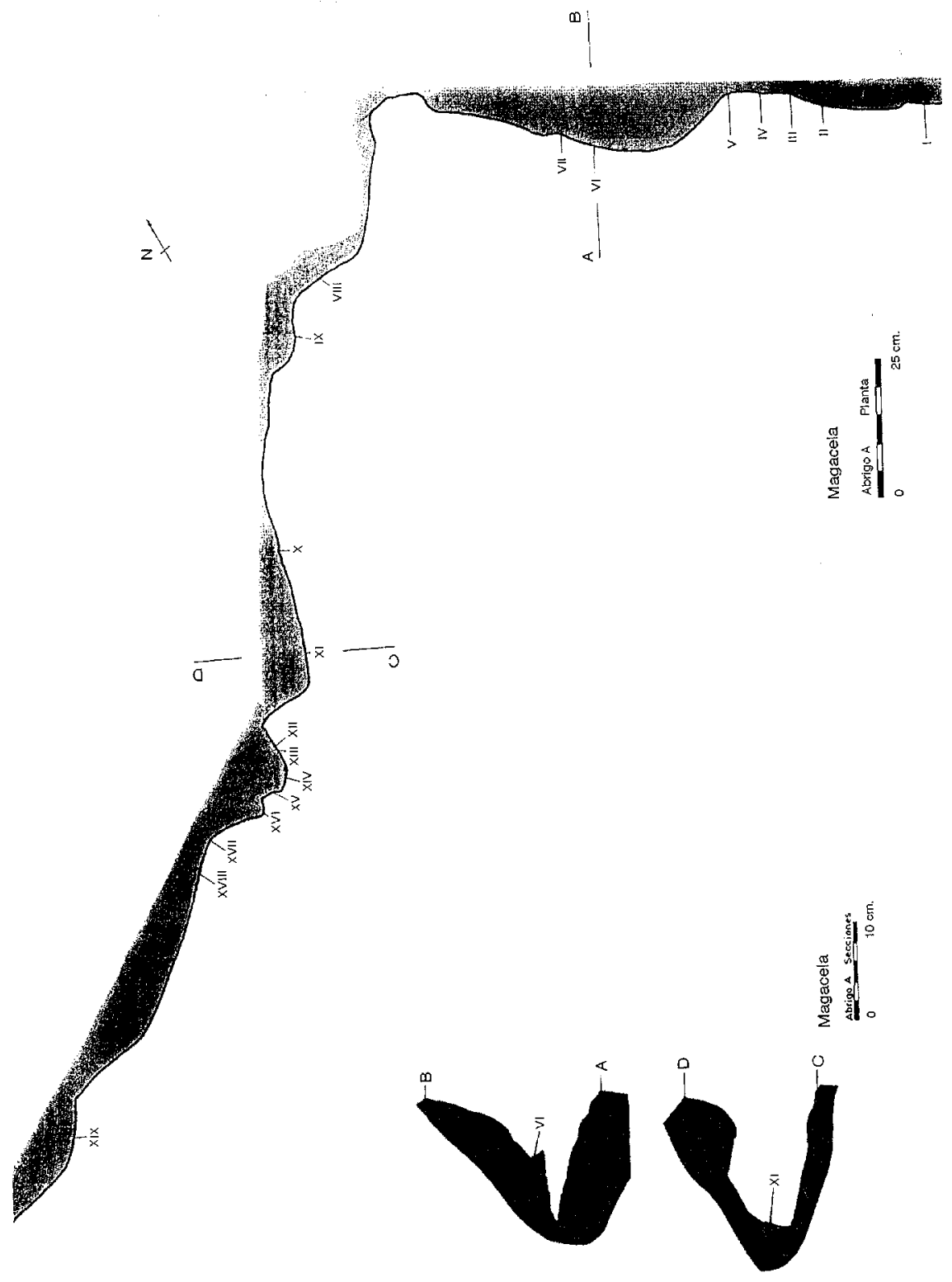

Figura 3. 
la medida de lo posible, las divisiones que de forma natural establecía el soporte (hornacinas, grietas, cuarteamientos, etc.).

El método de descripción que hemos seguido consiste en designar a cada grupo por medio de números romanos y dentro de cada grupo dar un número a cada motivo o grupo de motivos en el calco, respetando esta numeración a la hora de describirlos en el texto. Los grupos se numeran de derecha a izquierda desde el extremo NE del abrigo (fig. 3).

\section{Grupo I}

A.I.1. (fig. 4). Este primer motivo se sitúa a una altura desde el nivel de suelo de 1,04 $\mathrm{m}$. Se trata de un único trazo en vertical de $6,5 \mathrm{~cm}$. de altura $1 \mathrm{~cm}$. de ancho. Presenta un color rojo vinoso y un estado de conservación regular encontrándose más desvaído en su parte superior.

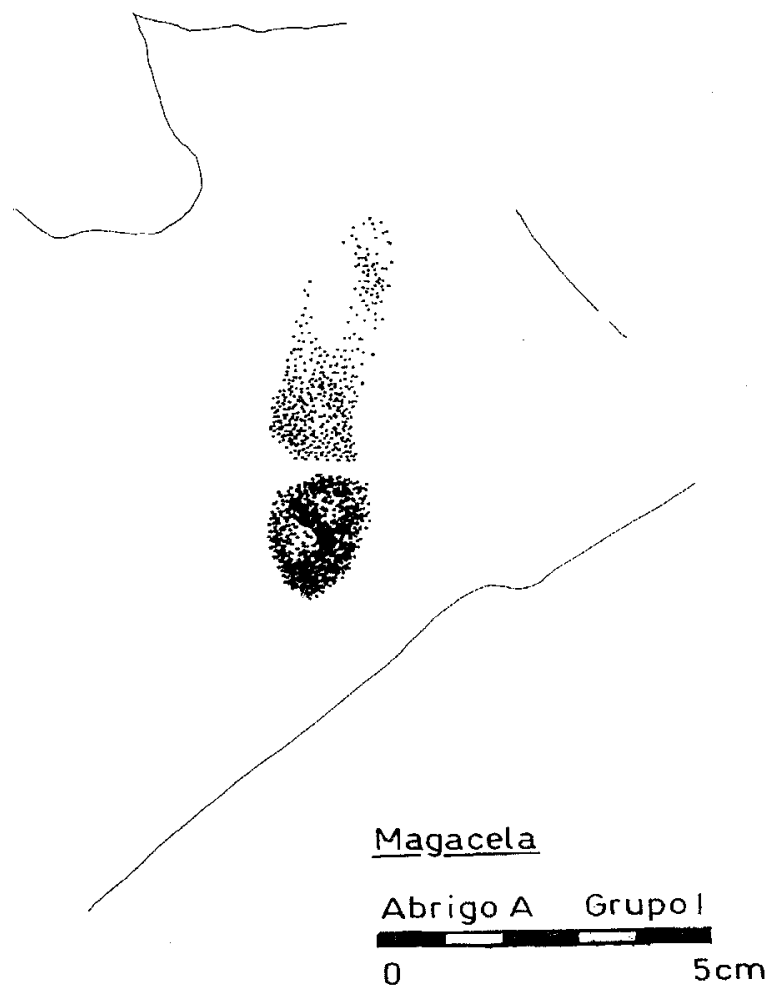

Figura 4. 
Grupo II

A.ll.1. (fig. 5). Un animal que con muchas reservas interpretamos como un perro, se une a la mano izquierda de un antropomorfo. La altura de la figura humana es de $6,8 \mathrm{~cm}$. y su ancho de $7,5 \mathrm{~cm}$. El animal mide $3,2 \mathrm{~cm}$. de altura máxima y $4,8 \mathrm{~cm}$. de longitud. Ambos presentan una tonalidad rojo vinosa, siendo excelente el estado de conservación del antropomorfo, no pudiendo decir lo mismo de la figura animal que se encuentra fuertemente desvaída.

A.ll.2. (fig. 5). A 2,10 m. a la izquierda y $1,30 \mathrm{~m}$. de altura, se localiza una figura humana masculina de cuyo brazo izquierdo, igual que del derecho, surgen una serie de plumas o flecos que podríamos considerar como adornos de la vestimenta con la que se le ha representado y de la que ha querido destacarse también un objeto indeterminado de forma rectangular que nuestra figura porta a la cintura.

A.ll.3. (fig. 5). Un pequeño trazo vertical a $5 \mathrm{~cm}$. por debajo del zoomorfo anterior, de $2,3 \mathrm{~cm}$. de altura y $0,6 \mathrm{~cm}$. de ancho en un color rojo muy mal conservado.

A.ll.4. (fig. 5). A su derecha encontramos un nuevo animal que ha perdido la parte anterior de la cabeza y una de las patas delanteras. Mide $3.4 \mathrm{~cm}$. de alzado y $4.4 \mathrm{~cm}$. de longitud. Su color es rojo vino y su estado de conservación excelente.

A.Il.5. (fig. 5). Inmediatamente por debajo y a su izquierda localizamos la parte anterior de un zoomorfo que únicamente conserva las dos patas anteriores completas y parcialmente una de las posteriores. En este caso el autor del conjunto pictórico lo ha representado en una postura forzada, como si estuviera rampante en relación con el resto de los animales de la agrupación. Mide $4 \mathrm{~cm}$. de altura y $4.1 \mathrm{~cm}$. de longitud. Su color es rojo vino similar al de la anterior figura y del mismo modo su estado de conservación es muy bueno.

A.II.6. (fig. 5). La última figura es un pequeño trazo en forma de anzuelo invertido de $1,3 \mathrm{~cm}$. de altura y $1 \mathrm{~cm}$. de ancho, de color rojo vinoso intenso y buen estado de conservación. No parece que este trazo pertenezca o forme parte de un motivo desaparecido, sino que quizá pueda tratarse, al no responder a ninguno de los esquematismos clásicos, de una prueba de tonalidad o de trazo que realizó en su momento el autor de la representación que nos ocupa. 


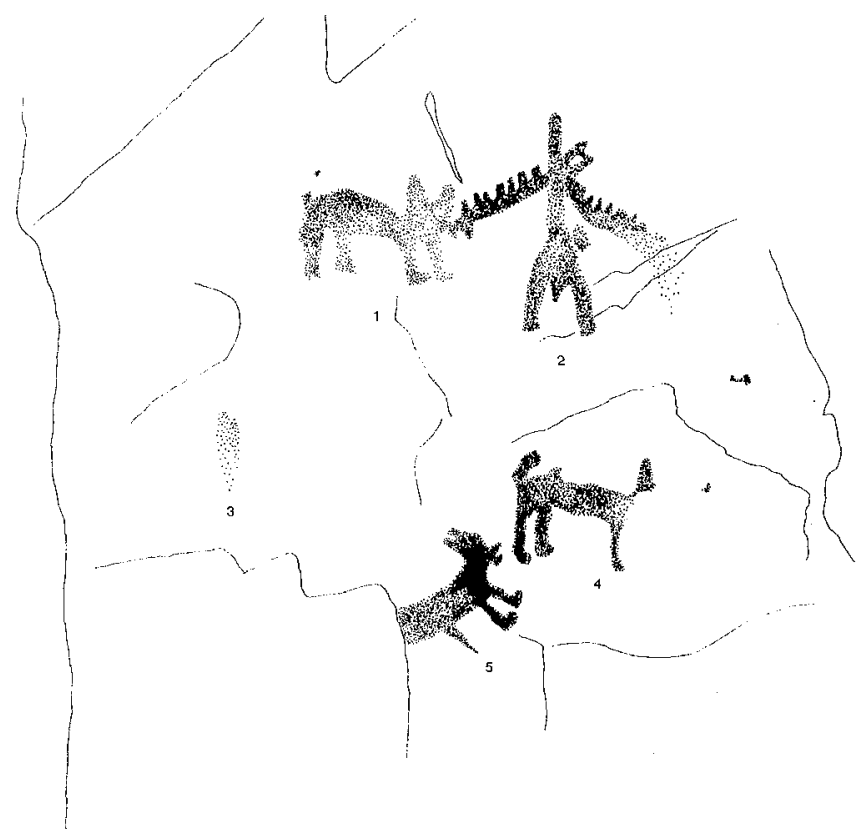

P

Figura 5. 


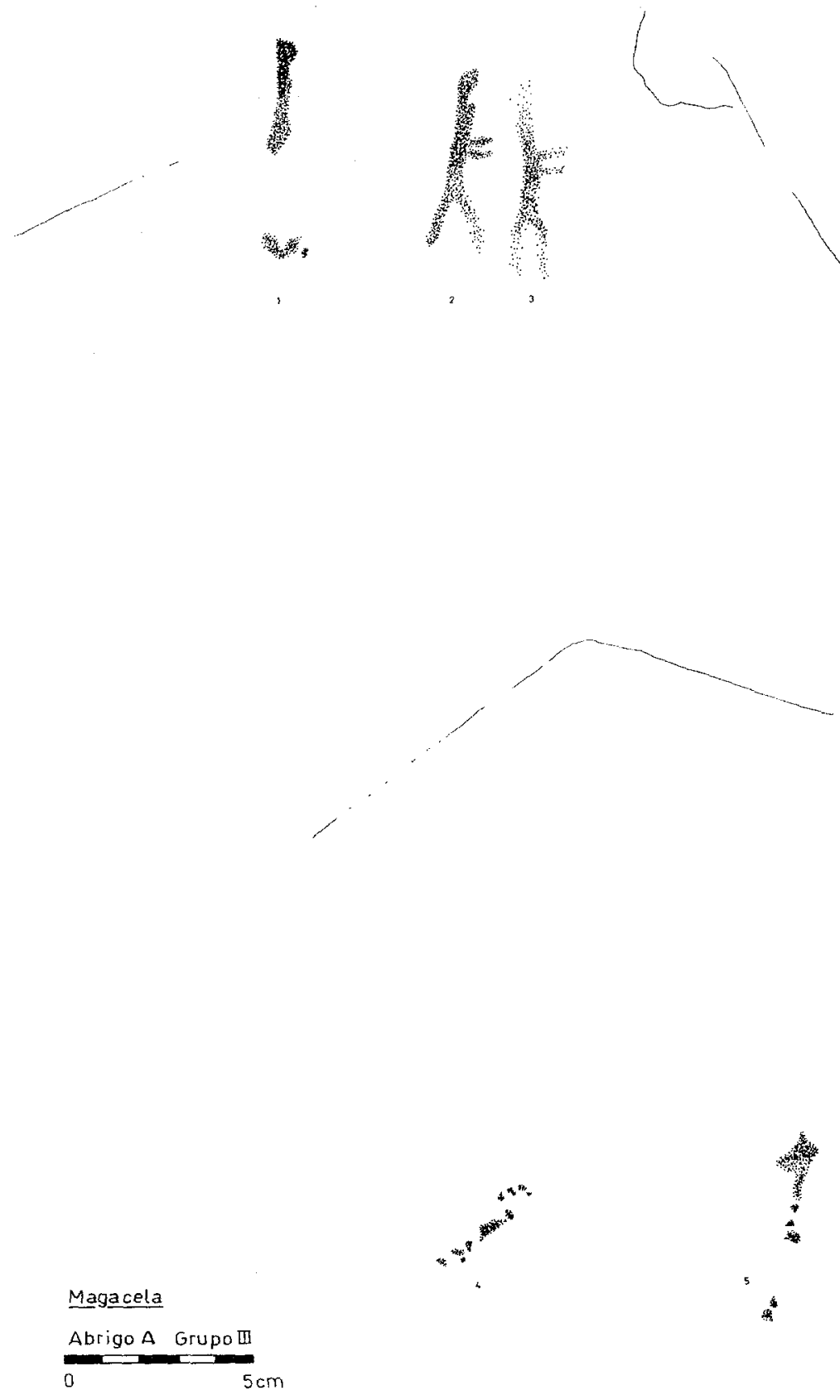

Figura 6. 
Grupo III

Desplazándonos $30 \mathrm{~cm}$. hacia la izquierda y a una altura desde el suelo de $90 \mathrm{~cm}$., encontramos esta nueva agrupación encabezada en su parte superior por una alineación de tres antropomorfos.

A.III.1. (fig. 6). Es la que presenta un estado de conservación más lamentable siendo sólo visible la cabeza, el tronco y parte de las extremidades inferiores. Mide $6,3 \mathrm{~cm}$. de altura y tiene un grosor máximo de $0,7 \mathrm{~cm}$.

A.III.2. (fig. 6). Esta figura que aparece a continuación, es la mejor conservada de las tres descritas. La cabeza se insinúa mediante un ligero estrechamiento del trazo para separarla del tronco. Los brazos se representan uno sobre el otro y las piernas formando $V$ invertida, contribuyen a dar al motivo una sensación de movimiento, como si los antropomorfos, colocados de perfil en fila india, estuvieran realizando algún tipo de desplazamiento, desfile o danza ritual. Tiene $5,4 \mathrm{~cm}$. de altura.

A.III.3. (fig. 6). El último de los motivos es muy similar al anterior aunque peor conservado en la cabeza y extremidades inferiores. Mide $5,7 \mathrm{~cm}$. de altura.

Los tres grafemas descritos presentan una intensa tonalidad rojo vinosa.

A.III.4-5. (fig. 6). Restos de pintura indescifrables de la misma tonalidad anterior situados $30 \mathrm{~cm}$. por debajo de los motivos anteriores.

A.III.6. (fig. 7). Unos $40 \mathrm{~cm}$. más abajo aún se localiza un motivo en forma de $V$ invertida, restos de lo que debió ser una figura más compleja, posiblemente un antropomorfo. Mide $3,1 \mathrm{~cm}$. de altura y $4 \mathrm{~cm}$. de ancho. Su color es rojo.

A.II.7. (fig. 7). Restos de una mancha de color no figurada y de similar tonalidad, se localiza a $3 \mathrm{~cm}$. por debajo de la representación anterior.

\section{Grupo IV}

Separado del grupo III por una fisura de la roca, a $30 \mathrm{~cm}$. hacia la izquierda y a $86 \mathrm{~cm}$. de altura desde el suelo, encontramos una de las agrupaciones más interesantes de este abrigo, no sólo por la clara superposición de motivos, sino también por las implicaciones jerárquicas que se deducen, tanto por el diferente tamaño, como por la posición que los grafemas ocupan dentro de la escena. 


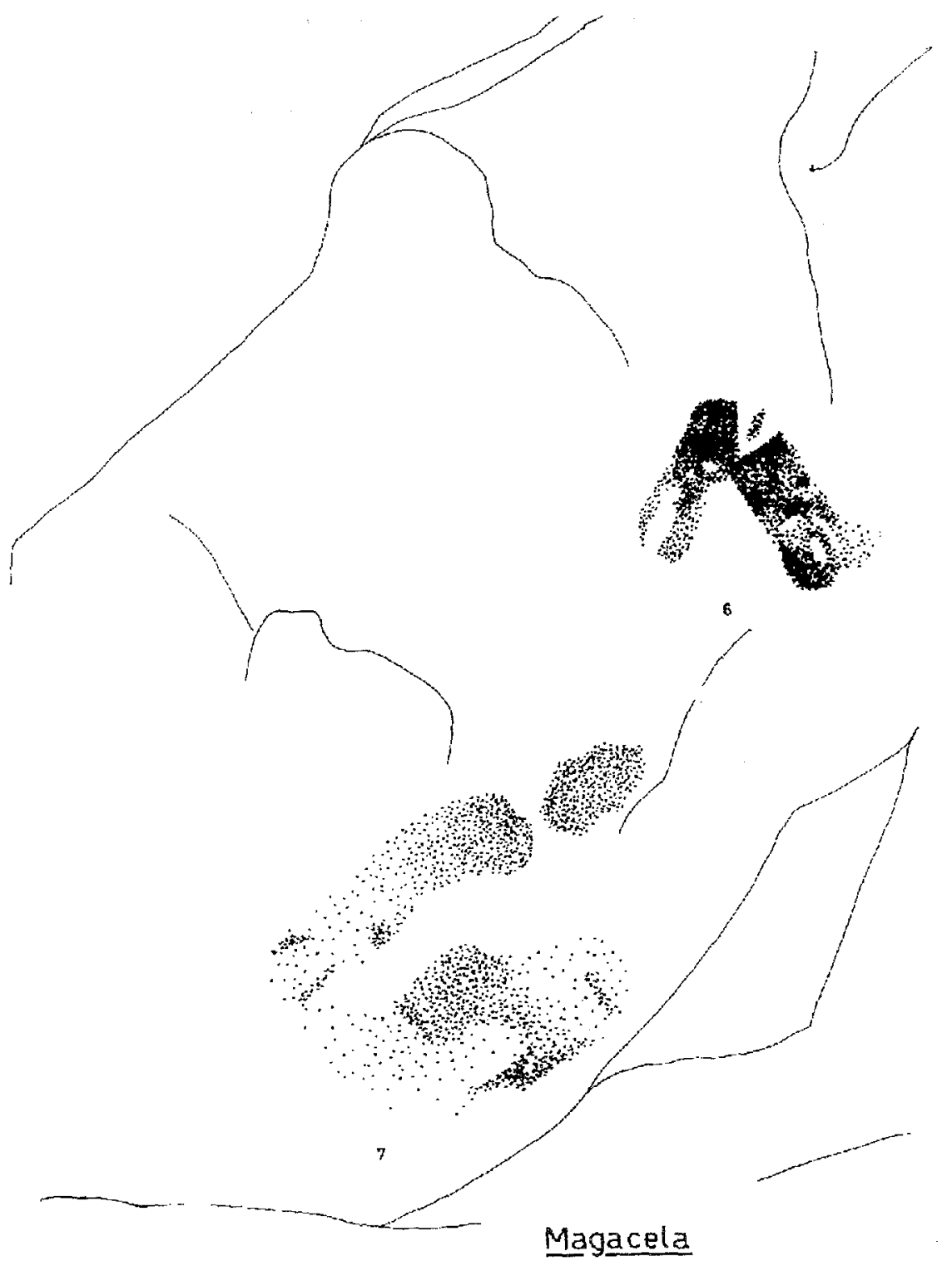

Abriga A Grupolll

0 $5 \mathrm{~cm}$

Figura 7. 
A.IV.1-2. (fig. 8). Son dos grandes figuras animales muy similares. Cabeza de forma triangular, con dos grandes orejas o cuernos, lomo alargado, cuatro patas y un largo rabo. Miden respectivamente 9 y $8,4 \mathrm{~cm}$. de altura y 25 y $23 \mathrm{~cm}$. de longitud. Fueron pintados en un tono anaranjado y su estado de conservación es bastante malo.

A.IV.3-4. (fig. 8). Superpuestos al primer animal, encontramos dos figuras humanas, una masculina y otra femenina, representadas con los mismos convencionalismos usados en los antropomorfos del grupo III, esto es, figura de perfil, brazos uno sobre otro y piernas formando $V$ invertida. El motivo masculino porta un objeto alargado entre sus brazos que podría considerarse como un arma o un bastón de mando en función de su mayor tamaño en relación con el resto de los antropomorfos de la escena y de su posición privilegiada dentro de la misma. A su lado está la figura femenina que a diferencia del anterior presenta una cabeza redondeada, bien individualizada del resto del tronco. El antropomorfo masculino mide $8,2 \mathrm{~cm}$. de altura y $4,2 \mathrm{~cm}$. de ancho, mientras que el femenino es ligeramente más pequeño, $7,5 \mathrm{~cm}$. de alto por $3,3 \mathrm{~cm}$. de anchura máxima. EI color de ambos motivos es rojo vinoso y su estado de conservación bueno.

A.IV.5. (fig. 8). Se localiza $35 \mathrm{~cm}$. hacia la derecha en una posición intermedia entre los dos antropomorfos anteriores y el conjunto inferior de 6 representaciones humanas. De tamaño notablemente inferior, $3.2 \mathrm{~cm}$. de altura por $1.5 \mathrm{~cm}$. de ancho, porta entre sus manos un objeto, posiblemente un arco. Su color es rojo vinoso y su estado de conservación es aceptable.

A.IV.6-11. (fig. 8). Diez centímetros por debajo observamos 6 nuevos motivos antropomorfos en cuya representación se han usado los mismos convencionalismos que hemos descrito para las figuras humanas del grupo III. El no 6 se diferencia de los anteriores por su tamaño inferior, $3,4 \mathrm{~cm}$. de altura y por presentar un tocado de dos plumas sobre la cabeza, mientras que en el $\mathrm{n}^{-} 7$ el autor ha querido plasmar el movimiento de la misma, flexionando para ello la pierna trasera de la figura y haciendo más corta la delantera. Su tamaño y el del resto de los antropomorfos es más o menos similar, $3,7 \mathrm{~cm}$. de alto por $1,1 \mathrm{~cm}$. de ancho. El color de todos los motivos es el mismo que se ha usado en las figuras anteriores, rojo vinoso y su estado de conservación es excelente.

A.IV.12. (fig. 8). Se localiza a $33 \mathrm{~cm}$. en diagonal hacia arriba y a la derecha. Se trata de una pequeña barra inclinada hacia la derecha y muy desvaída en su parte central. Mide $3,2 \mathrm{~cm}$. de longitud y su color es rojo vinoso.

A.IV.13 (fig. 8). A $18 \mathrm{~cm}$. por debajo aparece una mancha vertical (motivo 13) de pintura de $2,7 \mathrm{~cm}$. de longitud. Presenta un color anaranjado similar al de los zoomorfos 1 y 2 . 
4
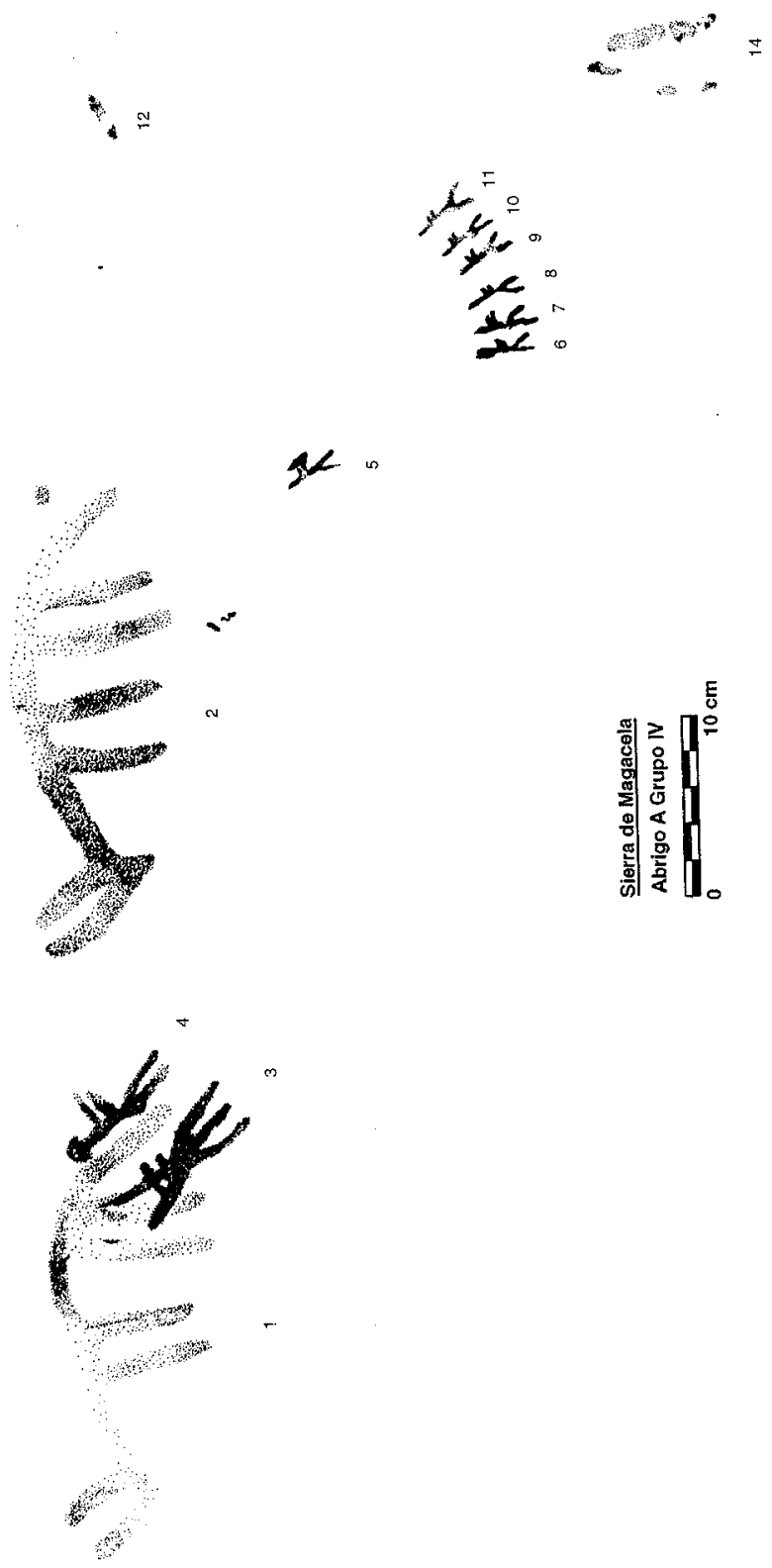

Figura 8. 
A.IV.14. (fig. 8). Continuando hacia abajo a una distancia de $11 \mathrm{~cm}$. encontramos los restos de dos barras formando ángulo de 7,5 y $6 \mathrm{~cm}$. de altura respectivamente realizadas en trazo grueso, tonalidad anaranjada y en un lamentable estado de conservación.

\section{Grupo V}

Se localiza a $86 \mathrm{~cm}$. a la izquierda del grupo anterior, en una pequeña superficie poligonal muy regular que forma un ligero ángulo con respecto al suelo del abrigo del que se encuentra separado solamente por $36 \mathrm{~cm}$.

A.V.1. (fig. 9). En la parte superior vemos una figura animal que hemos identificado como un cáprido representado en sus particularidades anatómicas (cuernos, hocico, rabo) de forma muy detallada y con grandes dosis de naturalismo. Mide $5 \mathrm{~cm}$. de longitud y $5,5 \mathrm{~cm}$. de altura máxima. Su color es rojo vinoso y su estado de conservación excelente.

A.V.2. (fig. 9). A su derecha encontramos unas líneas en zig-zag superpuestas, la superior más larga $(7,6 \mathrm{~cm}$.) que la inferior $(3,3 \mathrm{~cm}$.). Están realizadas en color similar al del no 1 y su estado de conservación es bueno.

A.V.3-6. (fig. 9). Por debajo aparecen manchas de pinturas en un color rojo vino intenso y en muy buen estado de conservación, por lo que considero que no constituyen restos de motivos más complejos, sino grafemas cuyo significado se escapa a nuestro corto entender, o bien pruebas de trazo o tonalidad que el autor del panel lleva a cabo con anterioridad a la realización de los motivos más complejos.

A.V.7. (fig. 9). Este grafema se encuentra convertido prácticamente en una mancha informe de color, pudiendo solamente apreciarse de forma clara tres trazos longitudinales que parten de la zona superior. Mide 2,9 $\mathrm{cm}$. de altura y $1,4 \mathrm{~cm}$. de ancho. Su color es rojo vinoso.

A.V.8. (fig. 9). Está un centímetro por debajo. Se trata de un motivo humano de características similares a los de otras agrupaciones (brazos superpuestos) y que se encuentra tocado, por lo que pudiera ser un casco de cuernos, muy parecido al que porta la figura representada en la estela de guerrero aparecida en esta localidad. Este antropomorfo cabalga sobre los restos (lomo y patas) de un animal muy mal conservado. Toda la figura se intercala en medio de una línea de puntos de $18 \mathrm{~cm}$. de longitud, que interpreto, bien como la representación de un camino o bien, como las huellas de un animal que son seguidas por el jinete. La altura de la figura es de $10,2 \mathrm{~cm}$. y su ancho $4 \mathrm{~cm}$. El color usado en todos los motivos es rojo vino y la conservación de las figuras es bastante regular. 


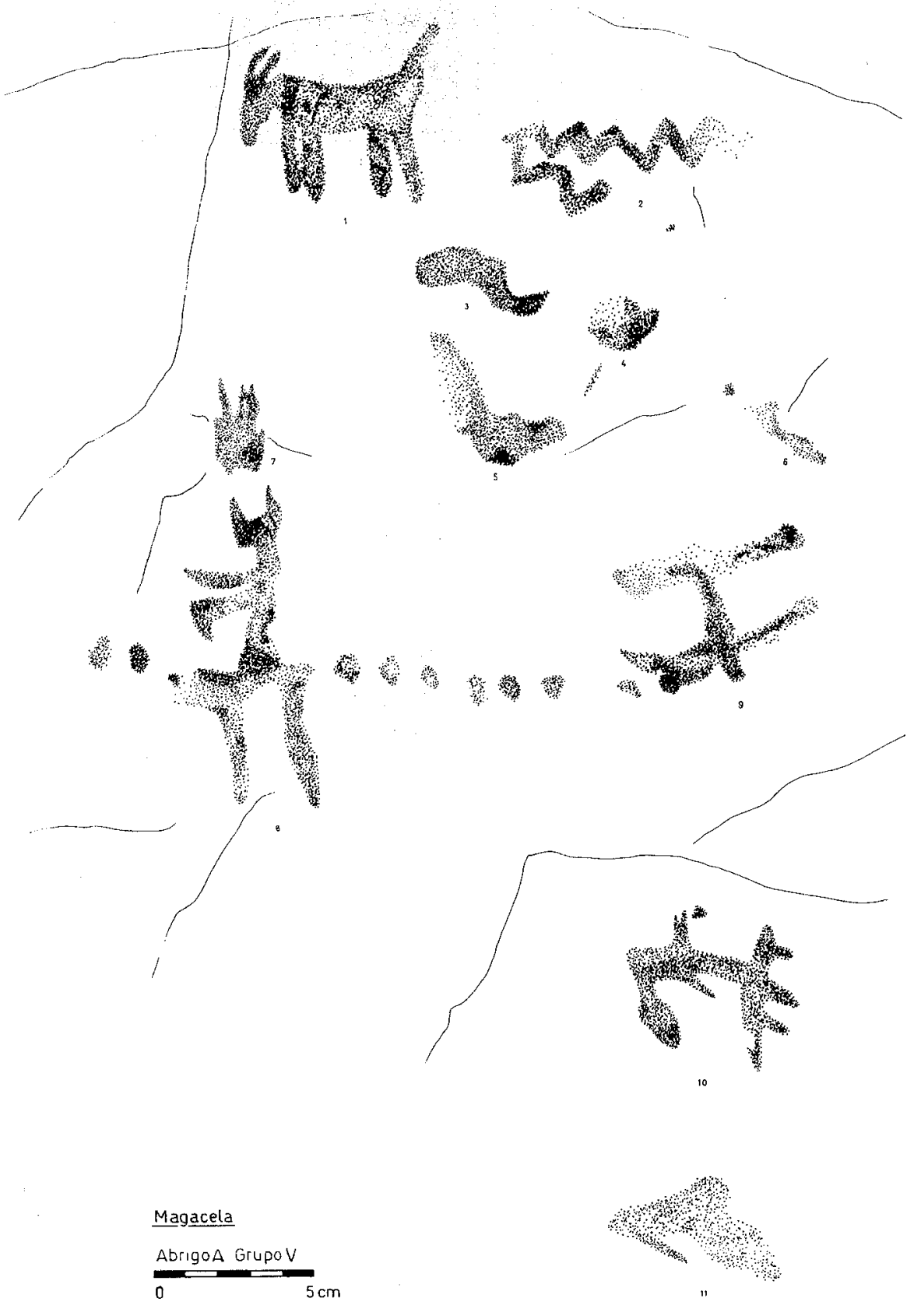

Figura 9. 
A.V.9. (fig. 9). Infrapuesto al último punto de la alineación encontramos un extraño grafema en forma de $\mathrm{H}$ inclinada. Mide $4,3 \mathrm{~cm}$. de altura y 5,9 $\mathrm{cm}$. de anchura máxima. La tonalidad es rojo vinoso y su estado de conservación es muy bueno.

A.V.10-11. (fig. 9). Continuando hacia abajo, a una distancia de $9 \mathrm{~cm}$., localizamos los dos últimos motivos, indeterminados dado su estado de conservación, del grupo V. El superior mide $4,5 \mathrm{~cm}$. de altura y $5,3 \mathrm{~cm}$. de longitud. El inferior tiene $5,5 \mathrm{~cm}$. de ancho y una altura de $3 \mathrm{~cm}$. El color empleado en su realización es rojo vinoso, igual al del resto de las figuras descritas en esta agrupación.

\section{Grupo VI}

Se localiza unos $85 \mathrm{~cm}$. en diagonal izquierda hacia abajo, en un entrante de la roca que forma ángulo de $90^{\circ}$ situado a $35 \mathrm{~cm}$. sobre el nivel del suelo. Las pinturas se distribuyen por la visera superior y la frontal, $y$ aparecen combinadas figuras realizadas en color rojo y negro, con tonalidades más o menos intensas, sin que se hayan podido constatar superposiciones.

A.VI.1. (fig. 10). Está situada en la visera superior, se trata de un pectiniforme incompleto, muy desvaído en la zona alta, de $12 \mathrm{~cm}$. de longitud y $6,8 \mathrm{~cm}$. de altura máxima. Su tonalidad es anaranjada y su estado de conservación malo.

A.VI.2. (fig. 10). Aparece en la visera frontal, un ancoriforme de $5,4 \mathrm{~cm}$. de altura y $3 \mathrm{~cm}$. de anchura máxima. Ha sido trazado en color negro y su conservación es bastante deficiente.

A.VI.3. (fig. 10). A su derecha localizamos un nuevo ancoriforme incompleto en su parte superior y ligeramente inclinado a la izquierda. Mide $6 \mathrm{~cm}$. de altura y $4,2 \mathrm{~cm}$. de anchura máxima. Su color es rojo vinoso y su estado de conservación malo.

A.V1.4. (fig. 10). Es un trazo curvado de cuya parte superior arranca otro vertical, ambos restos de un motivo indeterminado más complejo actualmente perdido. Mide $6,5 \mathrm{~cm}$. de altura. Está realizado en una tonalidad anaranjada y su conservación es pésima.

A.VI.5. (fig. 10). El siguiente motivo también incompleto, conserva únicamente cuatro trazos paralelos verticales de aproximadamente $4 \mathrm{~cm}$. de altura cada uno. Están hechos en un color rojo muy desvaído y su estado de conservación es deprorable. 


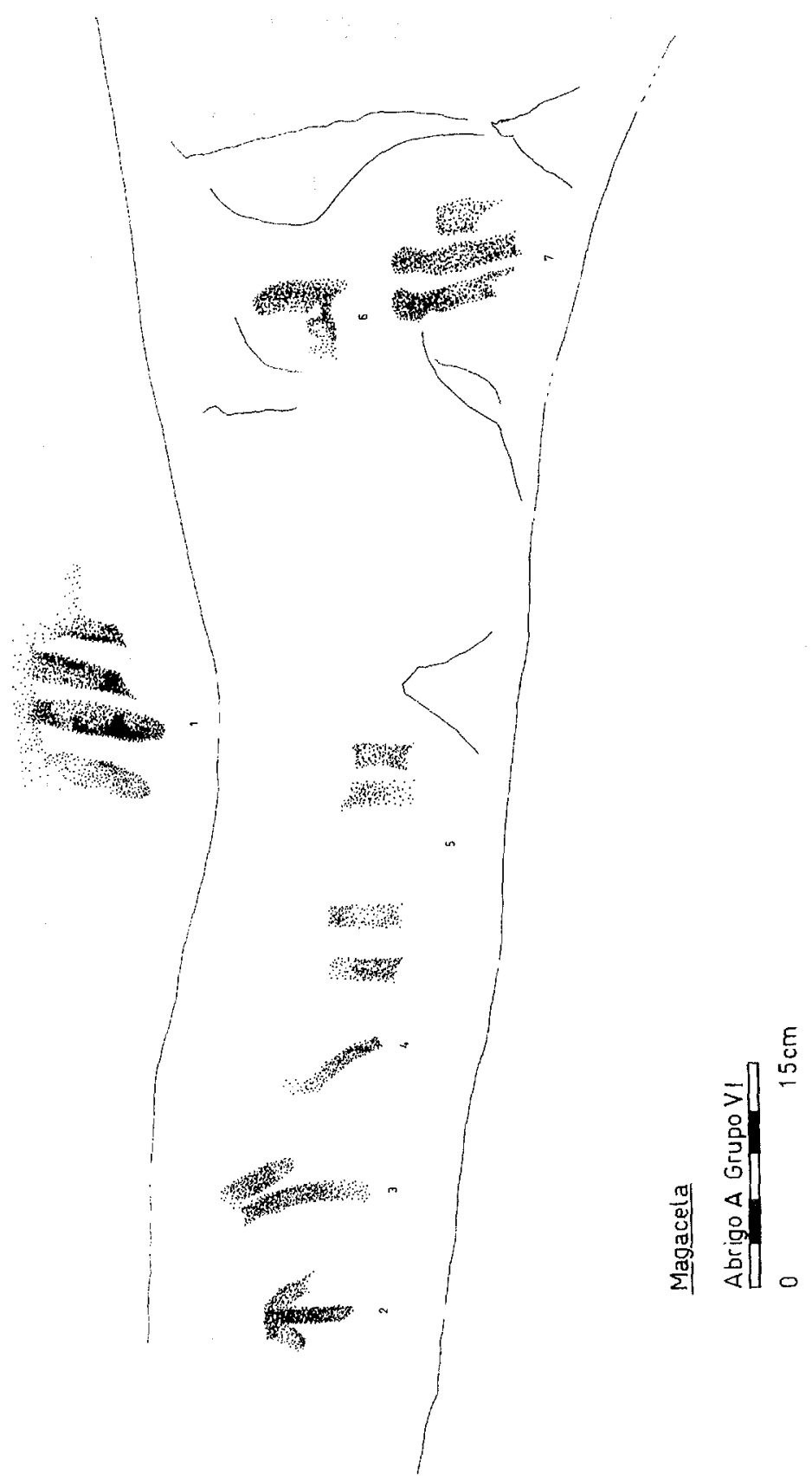

Figura 10. 
A.VI.6. (fig. 10). Es un extraño grafema indeterminado e incompleto. Mide $4 \mathrm{~cm}$. de longitud y $5 \mathrm{~cm}$. de altura máxima. Su color es rojo vinoso y su estado de conservación regular.

A.VI.7. (fig. 10). Tres centímetros por debajo aparecen tres barras verticales ligeramente inclinadas hacia la izquierda e incompletas en su tramo inferior. Miden 5, 6 y $3 \mathrm{~cm}$. de longitud respectivamente. Su color es rojo vinoso y su estado de conservación bueno.

A.VI.8. (fig. 11). Continuando hacia la derecha localizamos un grafema indeterminado de $5,5 \mathrm{~cm}$. de ancho y $6 \mathrm{~cm}$. de altura, color anaranjado y en pésimo estado de conservación.

A.VI.9. (fig. 11). La última figura del grupo VI es un interesante motivo, tanto por su tipología, un ídolo oculado, como por el color negro en el que ha sido representado. Mide $9,7 \mathrm{~cm}$. de altura por $7,5 \mathrm{~cm}$. de ancho y su estado de conservación es muy malo, habiendo desaparecido la práctica totalidad de la parte derecha del motivo.

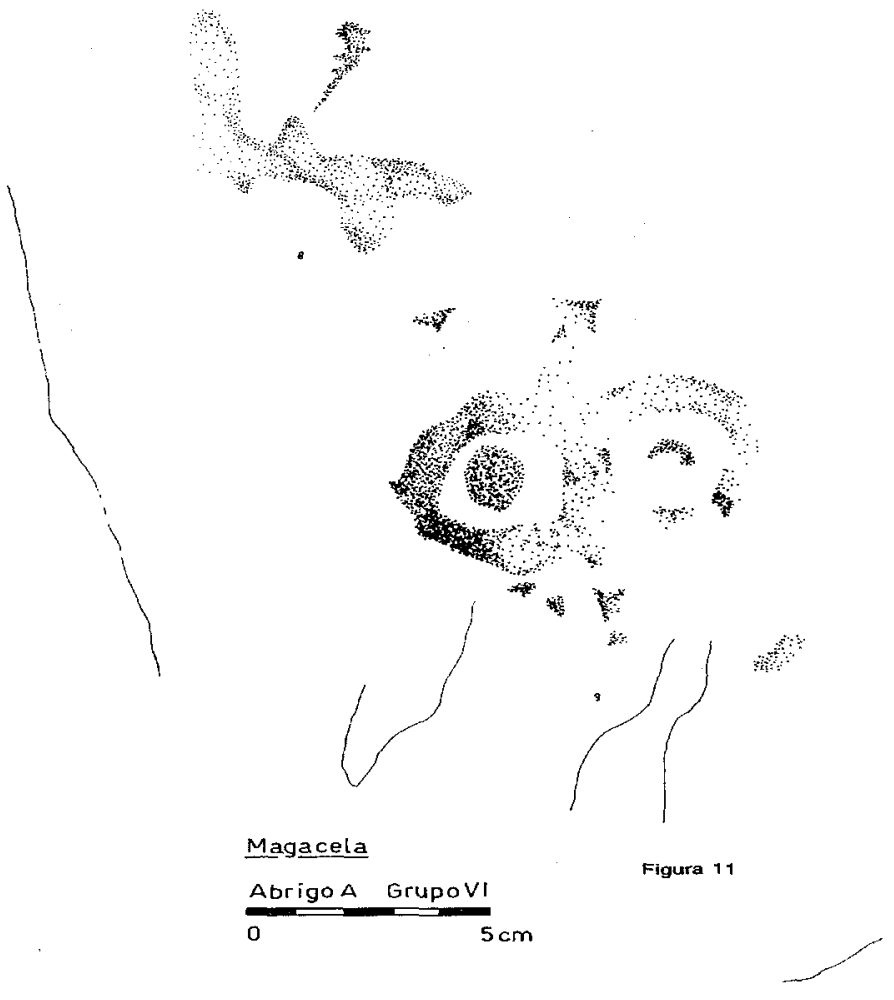

Figura 11. 
Grupo VII

A.VII.1. (fig. 12). Localizado a $97 \mathrm{~cm}$. hacia la izquierda desde el grupo anterior, está compuesto por un único motivo ancoriforme pintado en negro, en el que se pueden observar perfectamente las fases de realización del mismo, habiéndose trazado primero el arco transversal superior y posteriormente la línea vertical y el punto de la parte inferior derecha. Mide 6 $\mathrm{cm}$. de altura y $6,4 \mathrm{~cm}$. de longitud. Su estado de conservación es regular.

\section{Grupo VIII}

Se encuentra a $5,90 \mathrm{~m}$. en diagonal hacia la izquierda desde el grupo VII, y a una altura desde el suelo de $47 \mathrm{~cm}$., aprovechando la superficie más o menos plana de un gran saliente muy ennegrecida por efecto del humo y con un gran número de desconchones que han afectado en mayor o menor medida a las figuras.

A.VIII.1. (fig. 13). El primer motivo situado en la zona alta del panel es un animal muy afectado en su parte superior por un desconchado de la roca y del que sólo son visibles las cuatro patas (las dos delanteras muy desvaídas) unidas por la parte inferior del lomo, el arranque del cuello y lo

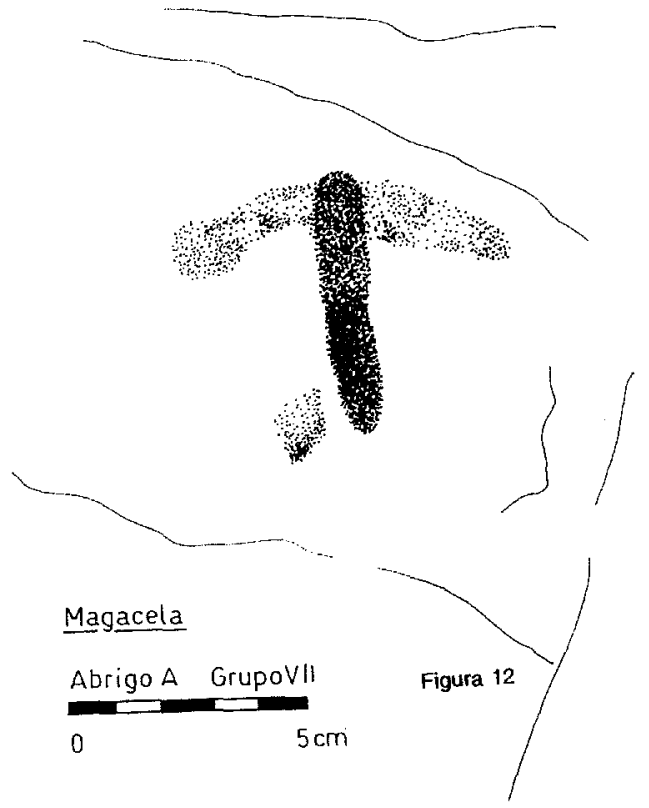

Figura 12. 


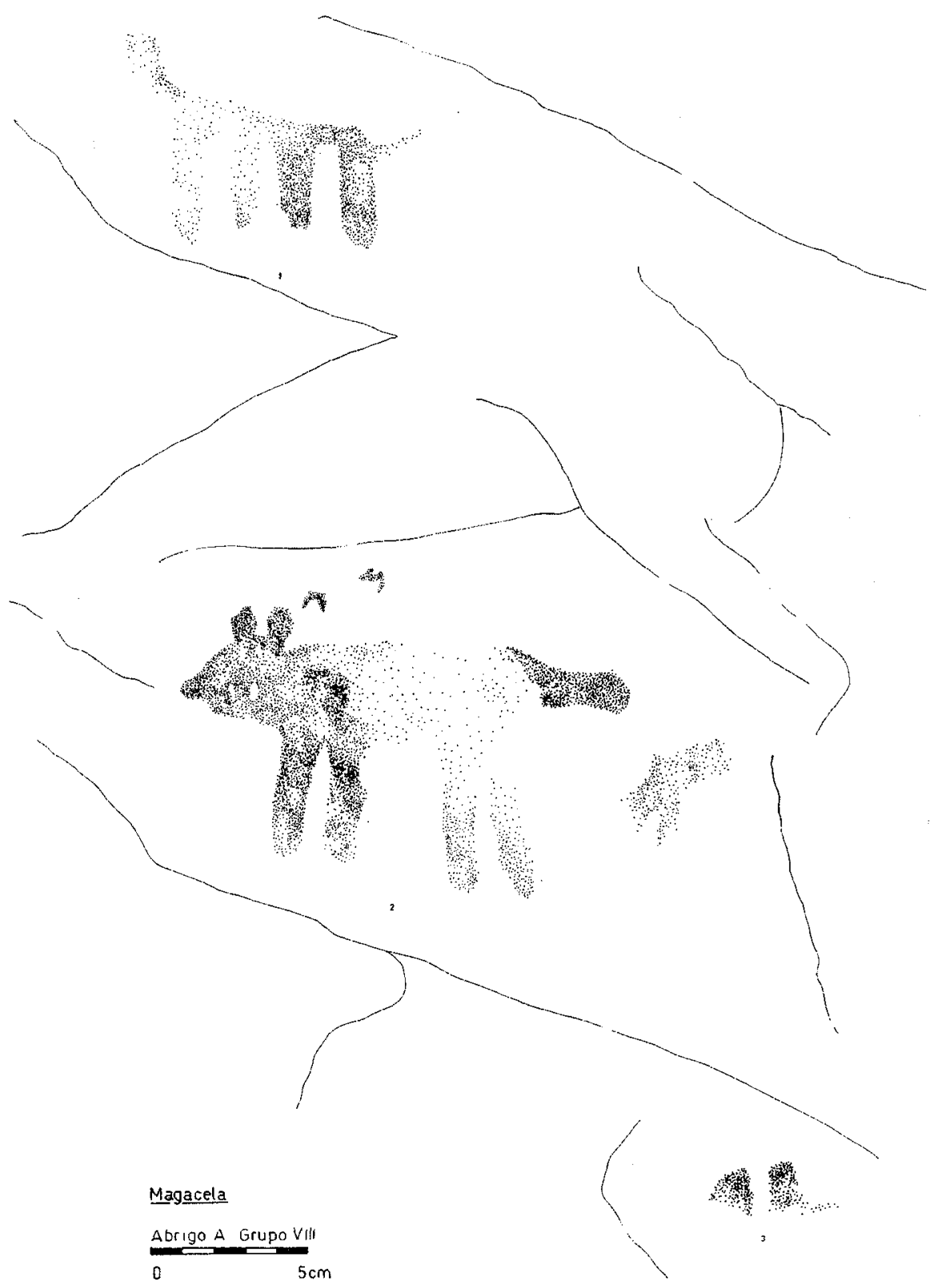

Figura 13. 
que queda de la cola. Mide $9,5 \mathrm{~cm}$. de longitud y 7 de altura. El color de la figura es rojo oscuro y su estado de conservación penoso.

A.VIII.2. (fig. 13). A $12 \mathrm{~cm}$. por debajo podemos observar un nuevo animal que podría ser considerado como un oso dado la forma redondeada de la cabeza y orejas, la forma del hocico y el cuerpo ovalado, gran parte del cual se halla prácticamente perdido. Mide $14,5 \mathrm{~cm}$. de longitud y $8 \mathrm{~cm}$. de altura. Su color es rojo oscuro y su estado de conservación es regular. A la derecha puede verse una mancha informe del mismo color, aunque mucho más desvaído.

A.VIII.3. (fig. 13). En diagonal derecha hacia abajo $10 \mathrm{~cm}$. observamos las dos orejas de un animal totalmente perdido por el arranque del pedazo de roca donde había sido dibujado. Lo conservado mide $4,3 \mathrm{~cm}$. de longitud y $1,5 \mathrm{~cm}$. de altura y está realizado en una tonalidad roja oscura similar a la del resto de las figuras de este grupo.

\section{Grupo IX}

A.IX.1. (fig. 14). En un pequeño cuarteamiento de la roca a unos 120 $\mathrm{cm}$. hacia arriba desde el anterior grupo y ligeramente a la izquierda nos encontramos con un conjunto de puntos colocados en dos hiladas, la su-

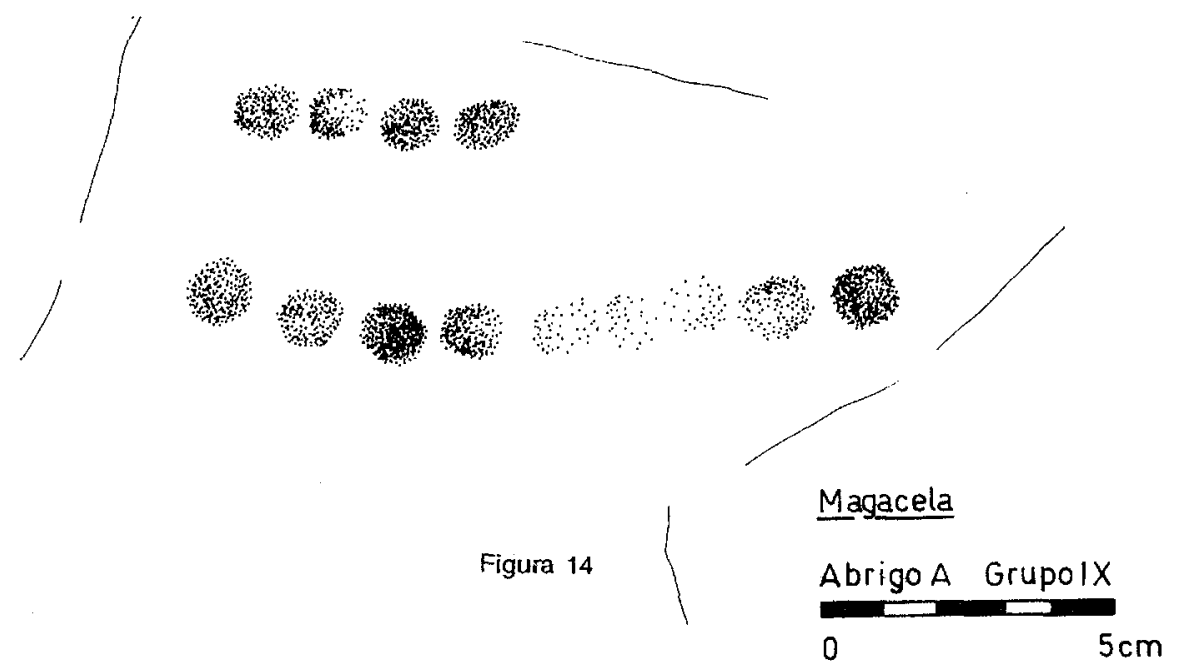

Figura 14. 
perior con cuatro y la inferior con nueve. El diámetro de todos es más o menos similar, entorno al centímetro, y están realizados en una tonalidad roja muy desvaída casi anaranjada. Su estado de conservación es malo, especialmente el de los puntos centrales de la línea inferior.

\section{Grupo X}

Se sitúa a la izquierda de la agrupación IX a unos 3,42 m. y a una altura sobre el suelo de 1,25 m. Está compuesta por cuatro figuras realizadas en rojo muy desvaído (motivos 1-3) y negro (motivo 4) y con una superposición clara del motivo número 4 sobre el 2 .

A.X.1. (fig. 15). Se localiza en el extremo superior derecho, muy mal conservada y perdida en su zona inferior. La parte visible tiene forma de $Y$ ligeramente inclinada a la izquierda. Mide $3 \mathrm{~cm}$. de altura por $1,9 \mathrm{~cm}$. de ancho.

A.X.2-4. (fig. 15). Por debajo, a la izquierda, aparecen dos pectiniformes el superior de un tamaño mayor $(16 \mathrm{~cm}$. de longitud por $7 \mathrm{~cm}$. de altura) que el inferior ( $10 \mathrm{~cm}$. de longitud por $5 \mathrm{~cm}$. de ancho), ambos en posición invertida. Su estado de conservación es regular.

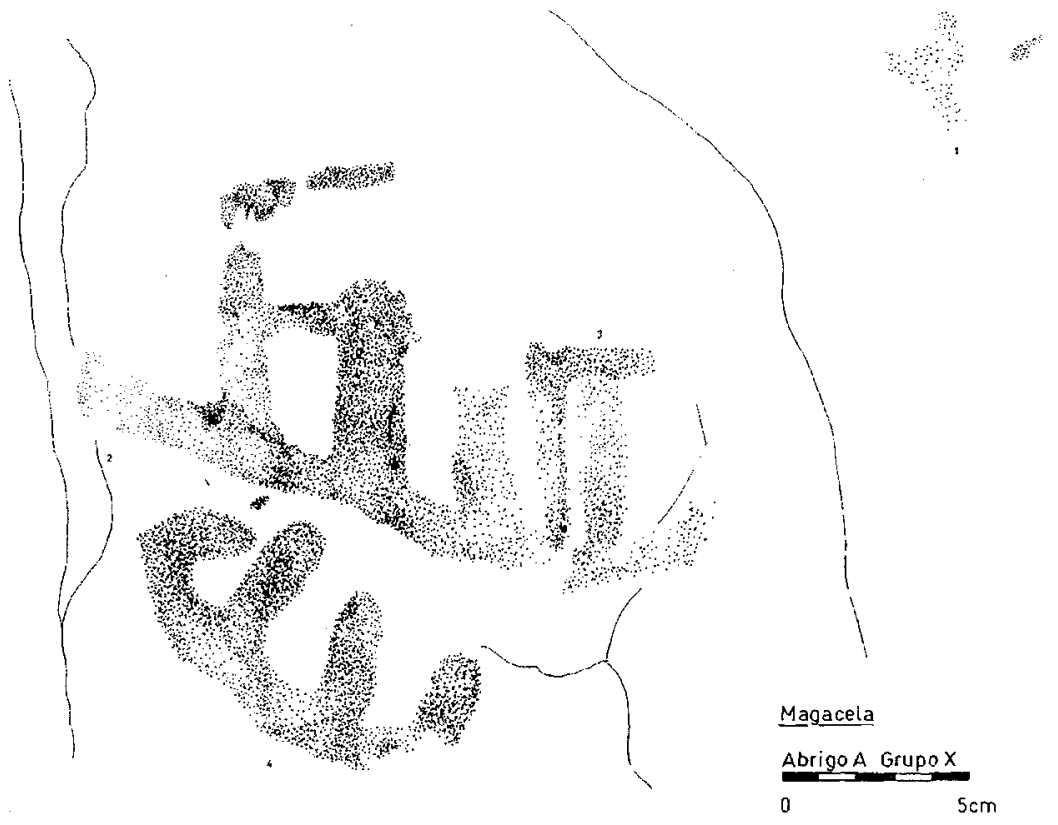

Figura 15. 
A.X.3. (fig. 15). Superpuesto al grafema 2 encontramos el motivo número 4 , que interpretamos como una figura ancoriforme que ha perdido la extremidad superior izquierda. Mide $5,6 \mathrm{~cm}$. de altura y $3,5 \mathrm{~cm}$. de longitud. Ha sido realizado en color negro y su estado de conservación es regular.

\section{Grupo XI}

A.XI.1. (fig. 16). A 1,25 m. en diagonal descendente hacia la izquierda a $24 \mathrm{~cm}$. del nivel de suelo vemos un esteliforme con once trazos radiales aún visibles no sin cierta dificultad. Por encima de la figura se han distribuido cuatro puntos y a la derecha de la misma pueden observarse restos de pintura indeterminados. Mide $8 \mathrm{~cm}$. de longitud por $10 \mathrm{~cm}$. de altura, está realizada en color rojo muy desvaído y su estado de conservación es pésimo en su zona inferior, siendo algo más visibles los cuatro rayos superiores y las puntuaciones.
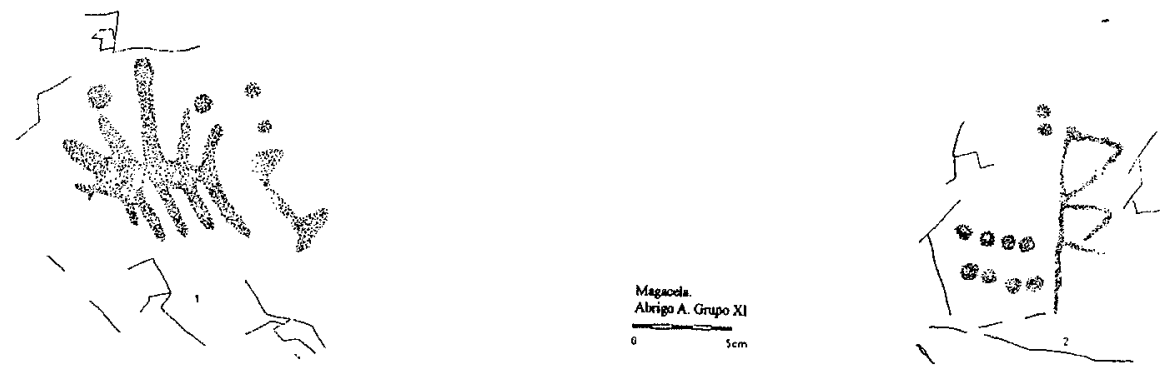

Figura 16.

A.XI.2. (fig. 16). Unos $40 \mathrm{~cm}$. a la derecha, en un entrante de la roca situado a $18 \mathrm{~cm}$. del suelo se observa un extraño motivo realizado en trazo fino sin paralelos próximos en la pintura esquemática peninsular, a no ser que los busquemos en las inscripciones indígenas prelatinas (abrigo del Castillo de Monfragüe, estelas de Almoroqui, Capote, Siruela y la pizarra con inscripciones de Cañamero) o en los grabados y pinturas sepulcrales de algunos dóimenes gallegos o portugueses. Mide $9,5 \mathrm{~cm}$. de altura y $3,3 \mathrm{~cm}$. de ancho. Su color es rojo vinoso oscuro, similar al de los antropomorfos superpuestos a las figuras animales del grupo IV y está muy bien conservado. A su izquierda aparecen una serie de puntos, dos en la parte superior alineados en vertical y otros dos alineamientos paralelos en la parte inferior compuestos por cuatro puntos cada uno. El diámetro de los mismos oscila entre $0,4 \mathrm{~cm}$. y $0,7 \mathrm{~cm}$. y están pintados en una tonalidad 
roja similar a la de los puntos que aparecen junto al esteliforme. Su estado de conservación es regular.

\section{Grupos XII-XV}

Los grupos XII, XIII, XIV y XV están sobre un gran saliente rocoso en forma de cubo prismático en cuyas caras laterales han sido representados los grafemas. El calco resultante supone el desarrollo de cada una de las caras de la roca en un único plano.

\section{Grupo XII}

A.XII.1. (fig. 17). Continuando hacia la izquierda a $2,42 \mathrm{~m}$. y a $30 \mathrm{~cm}$. sobre el nivel del suelo, en el lateral derecho del saliente rocoso, se encuentra un ancoriforme de $9,5 \mathrm{~cm}$. de altura por $6,5 \mathrm{~cm}$. de ancho realizada en color rojo muy claro casi anaranjado y en un lamentable estado de conservación.

\section{Grupo XIII}

A.XIII.2. (fig. 17). Situado $28 \mathrm{~cm}$. por encima del grupo anterior y ligeramente a la izquierda, observamos restos de figuras indeterminadas en muy mal estado de conservación siendo únicamente visible de forma clara una barra en posición vertical de $8,3 \mathrm{~cm}$. de altura y $0,7 \mathrm{~cm}$. de ancho. Todos los motivos son de tonalidad anaranjada muy desvaídos a causa de la profunda degradación (ennegrecimiento del soporte por el humo, desconchones y lavado por escorrentía) a que se han visto sometidos.

\section{Grupo XIV}

Sobre el frontal del cubo rocoso, a $52 \mathrm{~cm}$. de altura desde el nivel del suelo, encontramos una serie de motivos distribuidos en el soporte de forma vertical.

A.XIV.3. (fig. 17). En la zona alta vemos una barra, en posición vertical, ligeramente inclinada a la izquierda. Mide $5 \mathrm{~cm}$. de altura y el ancho del trazo es de $0,7 \mathrm{~cm}$. El color es rojo y su estado de conservación regular. 


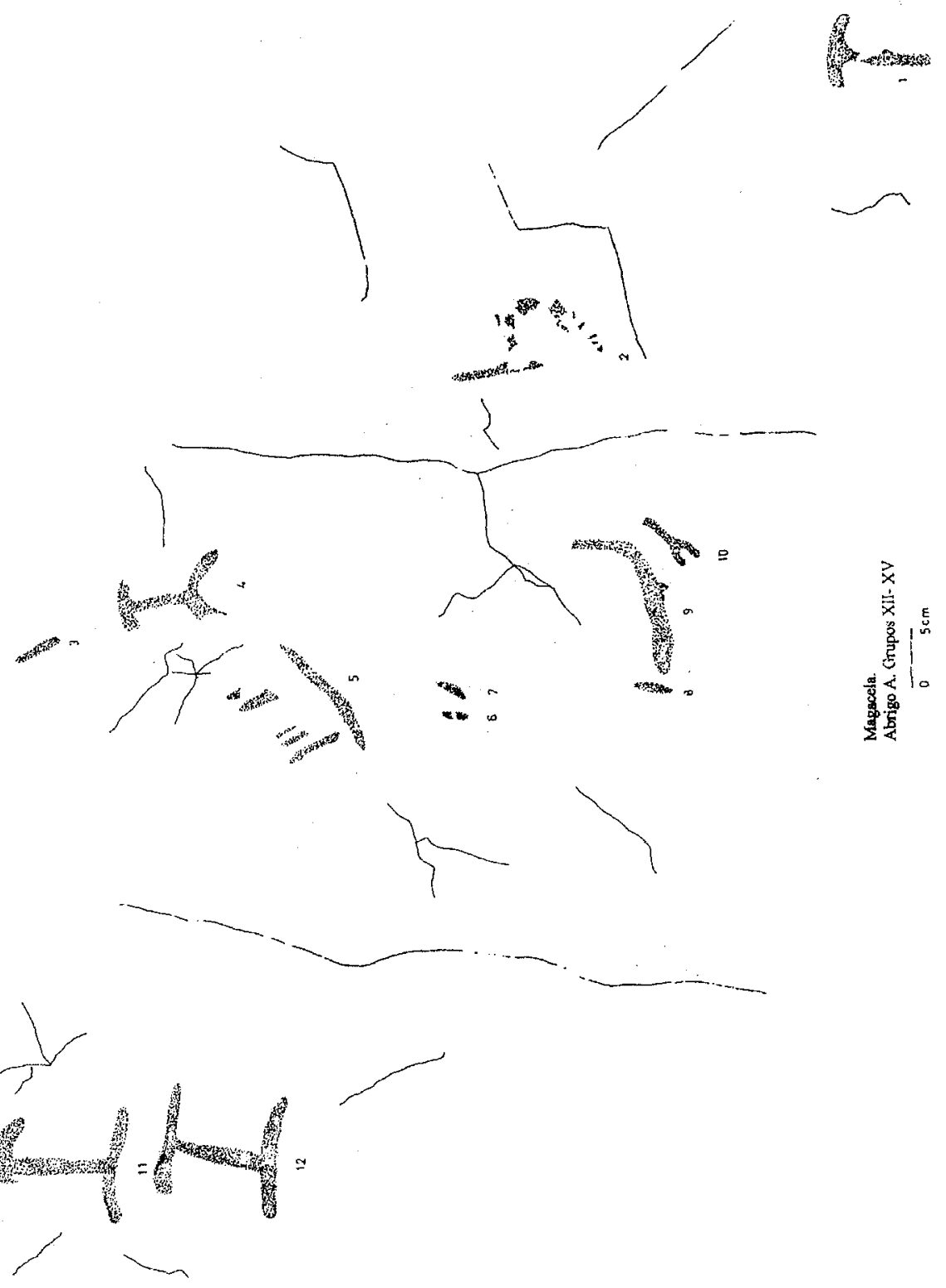

Figura 17. 
A.XIV.4. (fig. 17). Por debajo localizamos un motivo antropomorfo que ha perdido en parte las dos extremidades superiores y la inferior izquierda. Mide $12,3 \mathrm{~cm}$. de alto por $6,5 \mathrm{~cm}$. de ancho. Está realizado en color rojo y su estado de conservación es malo.

A.XIV.5. (fig. 17).- Ligeramente a su izquierda encontramos un grafema incompleto debido al lamentable estado de conservación en que ha llegado hasta nosotros. Una barra en posición horizontal a la que parecen confluir los restos de otras cinco barras perpendiculares a ella. Con muchas reservas lo interpretamos como un pectiniforme en posición invertida, similares a los de la agrupación número $X$, motivos que al igual que en este caso, están asociados a una figura humana próxima a ellos (en el grupo $X$ un ancoriforme en color negro se superpone a uno de los pectiniformes, en el grupo XIV el pectiniforme debemos entenderlo asociado al antropomorfo número 4). Las medidas del mismo son $13,9 \mathrm{~cm}$. de longitud por 8 de altura y la tonalidad del trazo es rojiza.

A.XIV.6-7. (fig. 17).- Continuando hacia abajo aparecen dos pequeñas barras verticales e inclinadas un poco a la derecha. La primera se encuentra dividida en dos fragmentos al haberse perdido su zona central. Mide $3 \mathrm{~cm}$. de alto y la anchura del trazo es de $0,7 \mathrm{~cm}$. La segunda se encuentra completa y tiene medidas similares. Ambas están trazadas en color rojo y su estado de conservación es muy malo.

A.XIV.8. (fig. 17).- Situada $15 \mathrm{~cm}$. por debajo, es una nueva barra vertical muy desvaída en su zona central. Mide $3.7 \mathrm{~cm}$. de altura y $0.7 \mathrm{~cm}$. de ancho. Su color es rojo claro y su estado de conservación es pésimo.

A.XIV.9. (fig. 17).- Inmediatamente a la derecha encontramos una barra horizontal curvada hacia arriba en su extremo derecho. Dos pequeños trazos verticales se insinúan arrancando de la zona inferior de la figura. Las características de este grafema son muy similares a las de una representación zoomorfa, siendo este motivo prácticamente igual al motivo 2 del grupo XIX, en la que el trazo curvado podría interpretarse como la cornamenta del animal o la cabeza del mismo. Todo ello nos lleva a considerar tambien el motivo número 9 de este grupo XIV como una representación zoomorfa. Mide $12 \mathrm{~cm}$. de longitud por $7 \mathrm{~cm}$. de alzado, su color es rojo claro y su estado de conservación lamentable.

A.XIV.10. (fig. 17).- Por debajo se sitúa un grafema incompleto que interpretamos como la parte inferior de un antropomorfo que ha perdido el arco transversal superior. De nuevo encontramos en este grupo la asociación de la figura animal con una representación antropomórfica. Mide 6 $\mathrm{cm}$. de longitud y $2,6 \mathrm{~cm}$. de altura y está realizado en color rojo similar al del resto de los motivos de este grupo, y del mismo modo al igual que el resto, su estado de conservación es lamentable. 
Grupo XV

A.XV.11-12. (fig 17).- Se encuentran en el lateral izquierdo del saliente rocoso a una altura desde el suelo de $97 \mathrm{~cm}$. Son dos figuras antropomorfas con las extremidades superiores e inferiores representadas prácticamente sin curvatura, casi en horizontal. Las medidas de ambas son similares: $10 \mathrm{~cm}$. de longitud por $10 \mathrm{~cm}$. de altura, su color es rojo y su estado de conservación regular, estando el motivo 11 más perdido, sobre todo en su zona superior, que el 12 , el cual conserva la totalidad de su trazado.

\section{Grupo XVI}

A $95 \mathrm{~cm}$. a la izquierda del grupo XV y a $70 \mathrm{~cm}$. de altura sobre el nivel del suelo vemos este nuevo conjunto de figuras en las que se han usado de forma independiente los colores rojo y negro.

A.XVI.I. (fig. 18).- La primera representación se localiza en la zona izquierda. Es un ancoriforme inclinado a la derecha con el trazo vertical desarrollado en exceso y que ha perdido la parte izquierda de la línea transversal superior en arco. Mide $10,5 \mathrm{~cm}$. de altura y $3,5 \mathrm{~cm}$. de longitud. Su color es rojo claro y su estado de conservación regular.

A.XVI.2. (fig. 18).- A su derecha vemos un trazo vertical paralelo al motivo anterior. Es posible que se tratara tambien de un ancoriforme, aunque su lamentable estado de conservación no permite aseverarlo. Mide 7,3 $\mathrm{cm}$. de altura y el ancho del trazo es de $0,9 \mathrm{~cm}$. Su color es rojo claro similar a la tonalidad del motivo anterior.

A.XVI.3. (fig. 18).- Es un antropomorfo que conserva una mínima parte del arco transversal superior, un trazo en vertical definiendo el tronco y las piernas en arco con un abultamiento en la parte central a modo de vulva mas que de falo, debajo de la cual se ha colocado una pequeña puntuación. La inclinación de la figura es la misma que la de los dos grafemas anteriores Mide $8 \mathrm{~cm}$. de altura por $5,7 \mathrm{~cm}$. de longitud, su color es rojo claro y su estado de conservación regular.

A.XVI.4. (fig. 18).- Continuando $10 \mathrm{~cm}$. hacia la derecha se observa una alineación vertical de 5 puntos de un diámetro medio de $0,7 \mathrm{~cm}$. excepto el superior de mucho menor tamaño $(0,3 \mathrm{~cm}$.). Son de color rojo claro y su estado de conservación es aceptable.

A.XVI.5. (fig. 18).- Está a $25 \mathrm{~cm}$. a la derecha desde la línea de puntos. Se trata de una única digitación en color negro. Mide $2 \mathrm{~cm}$. de altura y su estado de conservación es bastante malo. 

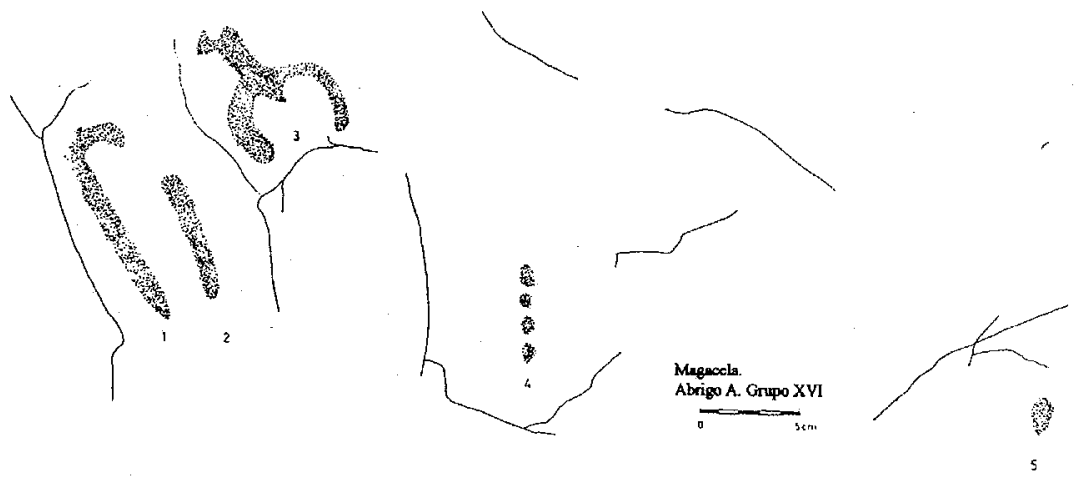

Figura 18.

\section{Grupo XVII}

A.XVII.I. (fig. 19).- Agrupación de tres barras verticales inclinadas a la izquierda, localizadas a $30 \mathrm{~cm}$. en diagonal izquierda hacia arriba y a 1,21 m. desde el suelo. Miden respectivamente $9 \mathrm{~cm} ., 9,2 \mathrm{~cm}$. y $11,5 \mathrm{~cm}$. Están trazadas en color rojo claro y su estado de conservación es regular.

A.XVII.2. (fig. 19).- Por debajo del anterior, a $6 \mathrm{~cm}$., aparece un trazo en horizontal incompieto de $5,5 \mathrm{~cm}$. de longitud de coloración similar y en pésimo estado de conservación.

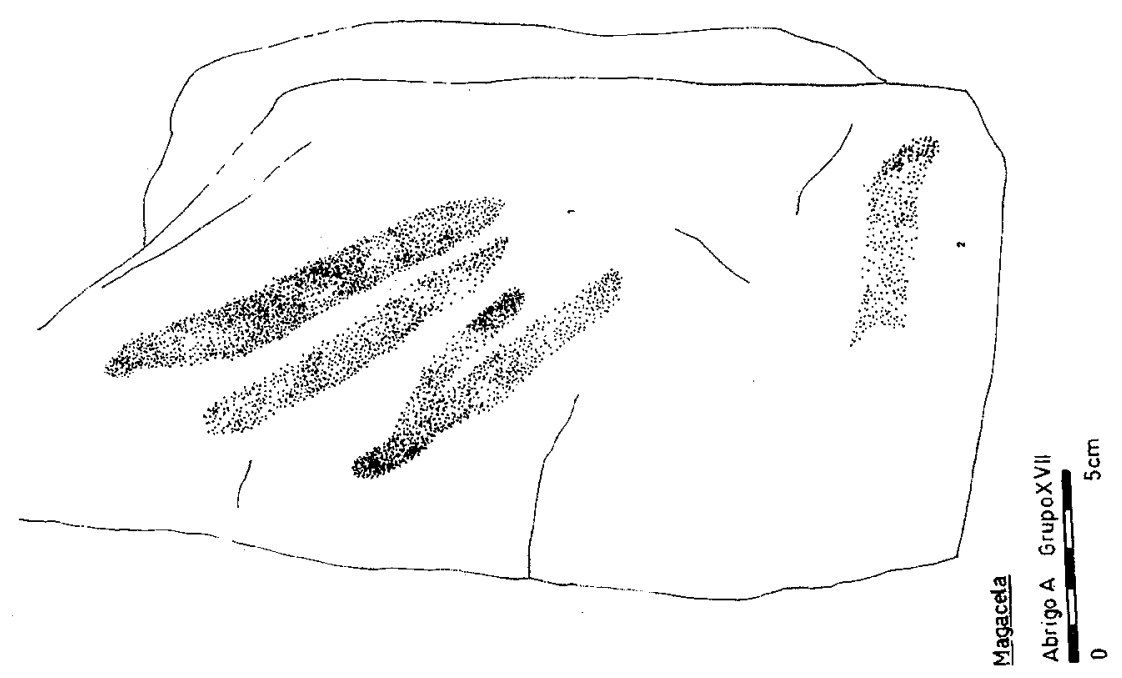

Figura 19. 
Grupo XVIII

A.XVIII.I. (fig. 20).-Esta formado por un solo motivo, un soliforme situado a $45 \mathrm{~cm}$. del grupo XVII en diagonal izquierda hacia abajo y a 1,01 m. desde el nivel de suelo. Conserva únicamente ocho de sus radios, estando prácticamente perdida la zona superior de la figura. Mide $7,5 \mathrm{~cm}$. de altura y $10 \mathrm{~cm}$. de longitud. Su color es rojo y su estado de conservación malo.

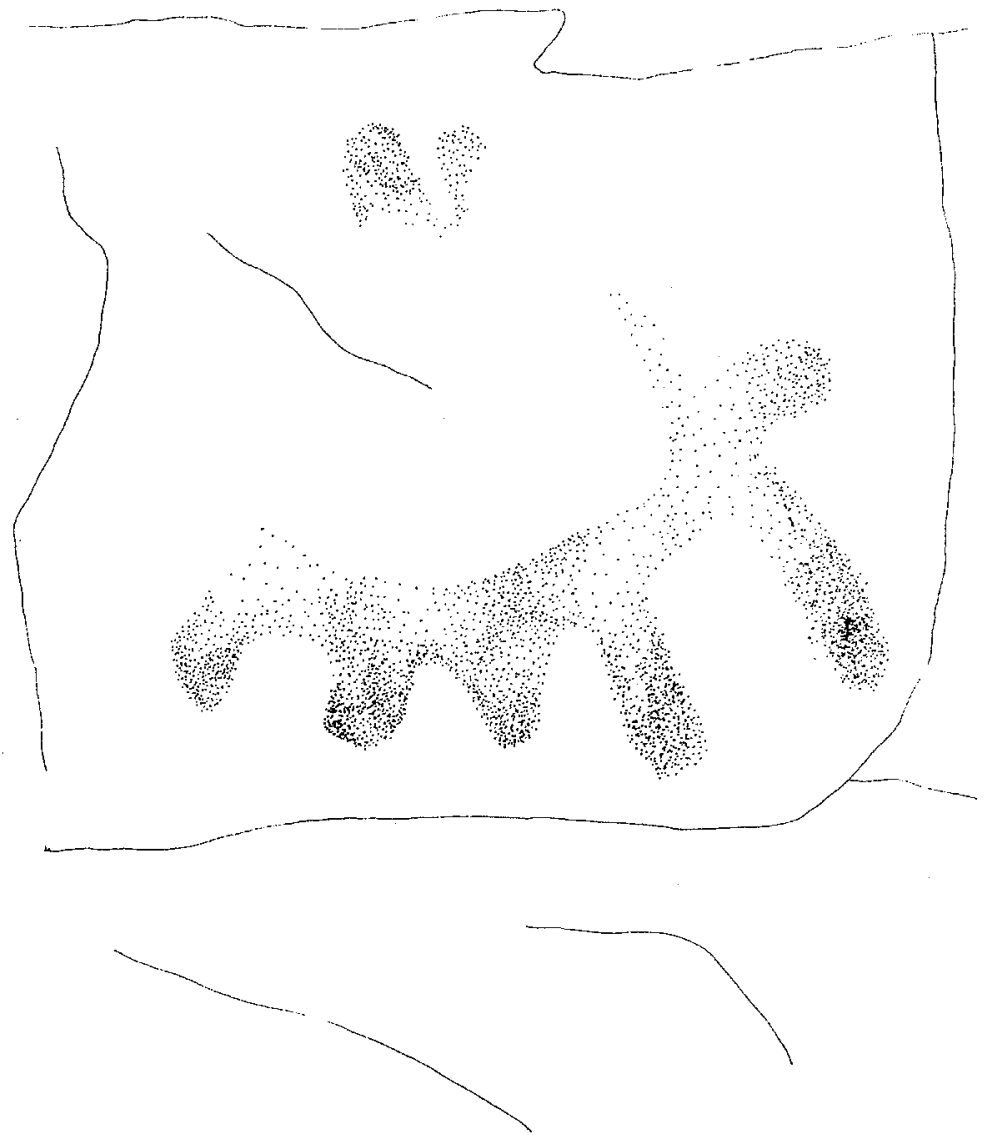

Magacela

Abrigo A GrupoXVIII

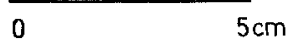

Figura 20 


\section{Grupo XIX}

Este último grupo se localiza en la parte inferior de una gran roca orientada $\mathrm{N}-\mathrm{S}$ en el extremo SE del abrigo a $9,10 \mathrm{~m}$. a la izquierda desde el grupo XVIII y a $50 \mathrm{~cm}$. de altura desde el suelo. De nuevo nos encontramos con una asociación antropomorfo-zoomorfo.

A.XIX.1. (fig. 21).- Un ancoriforme en la parte alta, incompleto en su extremidad superior derecha de $6,3 \mathrm{~cm}$. de altura por $3,5 \mathrm{~cm}$. de ancho, de color rojo y en lamentable estado de conservación.

A.XIX.2. (fig. 21).- Por debajo se sitúa una representación animal con cuatro patas, cola y lo que podría considerarse como un cuello excesivamente desarrollado o la representación de una cornamenta. Esta figura es de características similares al motivo número 9 del grupo XIV. Mide $9,5 \mathrm{~cm}$. de longitud y $10 \mathrm{~cm}$. de alzado. Su color es rojo y su estado de conservación muy malo.

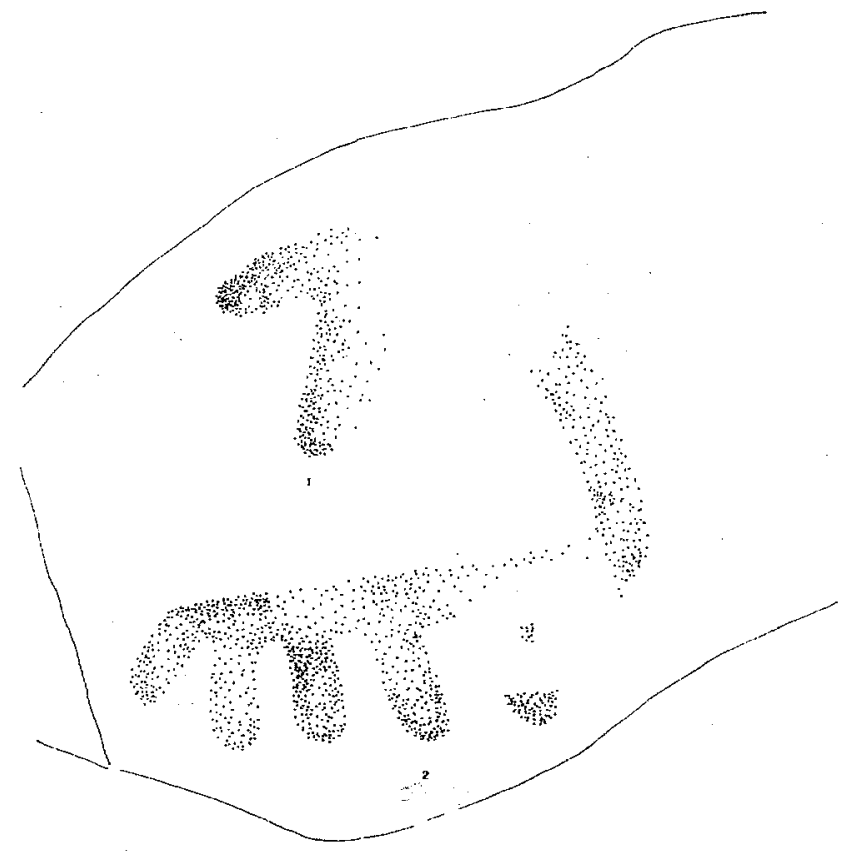

Magacela

Abrigo A Grupo $x i x$

0

Figura 21. 


\section{Abrigo $B$}

Esta segunda estación pictórica no se encuentra muy alejada de la anterior aunque se sitúa en la vertiente contraria (oeste), a una altura aproximada de $480 \mathrm{~m}$. y orientada NW-SE (hoja del S.E.G. 1/50.000 $\mathrm{n}^{\circ} 779$, designación: 30STJ611101).

El acceso al abrigo se realiza partiendo tambien desde el transformador de alimentación, continuando por la vereda hasta el tercero de los riscos de la sierra, desde donde puede observarse una gran fisura horizontal en la roca de $16,80 \mathrm{~m}$. de longitud, 1,66 $\mathrm{m}$. de altura máxima y $3,30 \mathrm{~m}$. de profundidad, abierta hacia una pequeña plataforma en la que aún son visibles restos de una antigua cerca de piedras, prácticamente destruida, indicativo del uso que tuvo el abrigo como resguardo de ganado. Esta utilización, junto con el ennegrecimiento de la roca a causa del humo de las hogueras y los numerosos desconchones, han afectado gravemente a las pinturas, habiendo llegado hasta nosotros únicamente tres grupos de figuras en no muy buen estado de conservación.

El método de descripción empleado es similar al utilizado en el abrigo A, dividiendo las representaciones en grupos en función de las divisiones naturales del soporte (fig. 22)
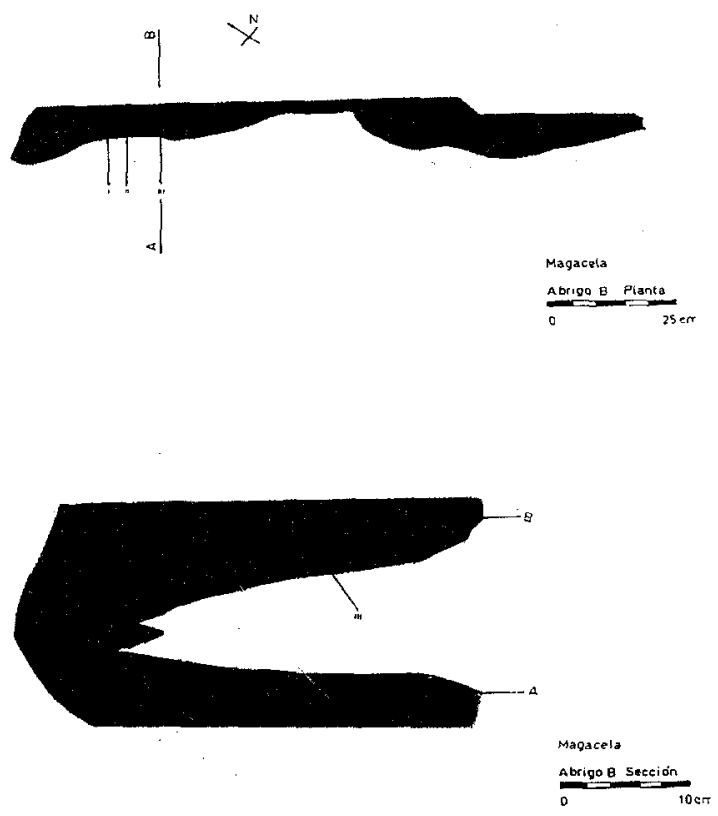

Figura 22. 


\section{Grupo I}

Se sitúa a $8,40 \mathrm{~m}$. desde el extremo NW del abrigo y a $90 \mathrm{~cm}$. de altura desde el suelo, sobre la superficie plana de un pequeño cuarteamiento de la roca, en la parte externa de la fisura.

B.I.I. (fig. 23).- Nos hallamos ante un motivo muy desvaído a base de trazos en posición vertical de tonalidad anaranjada sobre la cual se han repintado nuevos trazos y puntuaciones de una tonalidad rojo vinosa mucho más intensa y en mejor estado de conservación. El motivo infrapuesto mide $10 \mathrm{~cm}$. de longitud y $12 \mathrm{~cm}$. de altura, mientras que los superpuestos oscilan entre los 4 y $3 \mathrm{~cm}$. de altura para las barras y los $0,7 \mathrm{~cm}$. y $1,5 \mathrm{~cm}$. de diámetro para las puntuaciones. El estado de conservación general de la agrupación es malo.

\section{Grupo II}

Inmediatamente a la derecha del grupo anterior y sobre el techo del abrigo, a $85 \mathrm{~cm}$. de altura desde el nivel de suelo, encontramos un nuevo conjunto de motivos pintados en dos momentos diferentes.

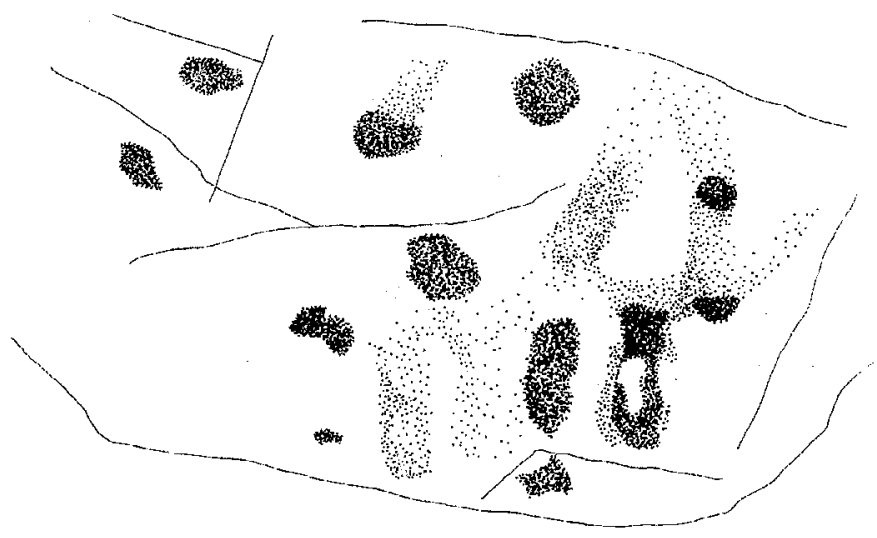

Magacela

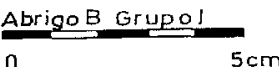

Figura 23 


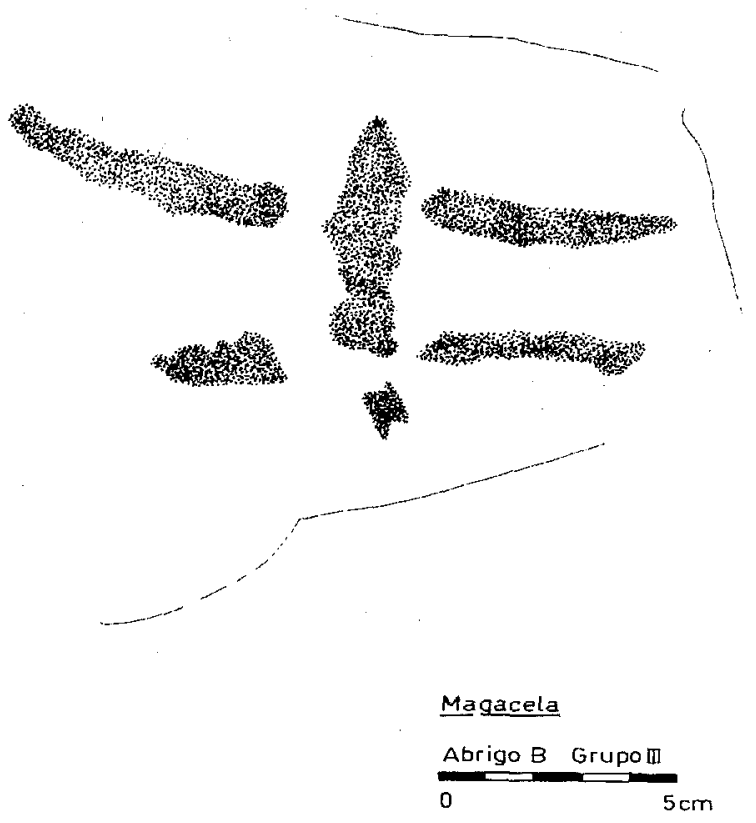

Figura 24.

B.Il.1-2. (fig. 25).- De la primera fase se conservan solamente dos pequeñas barras inclinadas en la parte superior derecha, con una tonalidad anaranjada similar al motivo infrapuesto del grupo I. Miden 3,2 y $3,5 \mathrm{~cm}$. de longitud respectivamente y su estado de conservación es muy malo.

B.Il.3-15. (fig. 25).- Por debajo aparecen una serie de puntuaciones y barras, algunas unidas por la parte superior formando ángulo (motivo 8). Están realizadas en color rojo vinoso y constituyen la segunda fase de motivos pintados en este grupo. Su estado de conservación es regular.

\section{Grupo III}

B.III.I. (fig. 24).- Se localiza a $70 \mathrm{~cm}$. hacia la derecha y a $96 \mathrm{~cm}$. de altura desde el suelo. Un único motivo formado por una barra vertical con una pequeña puntuación en la parte inferior y cuatro barras horizontales en cada uno de los ángulos que no llegan a unirse a la vertical. Mide 15 $\mathrm{cm}$. de longitud y $9 \mathrm{~cm}$. de altura y está hecha en el color rojo vinoso igual al empleado en los motivos de la segunda fase de este abrigo. Su estado de conservación es aceptable. 

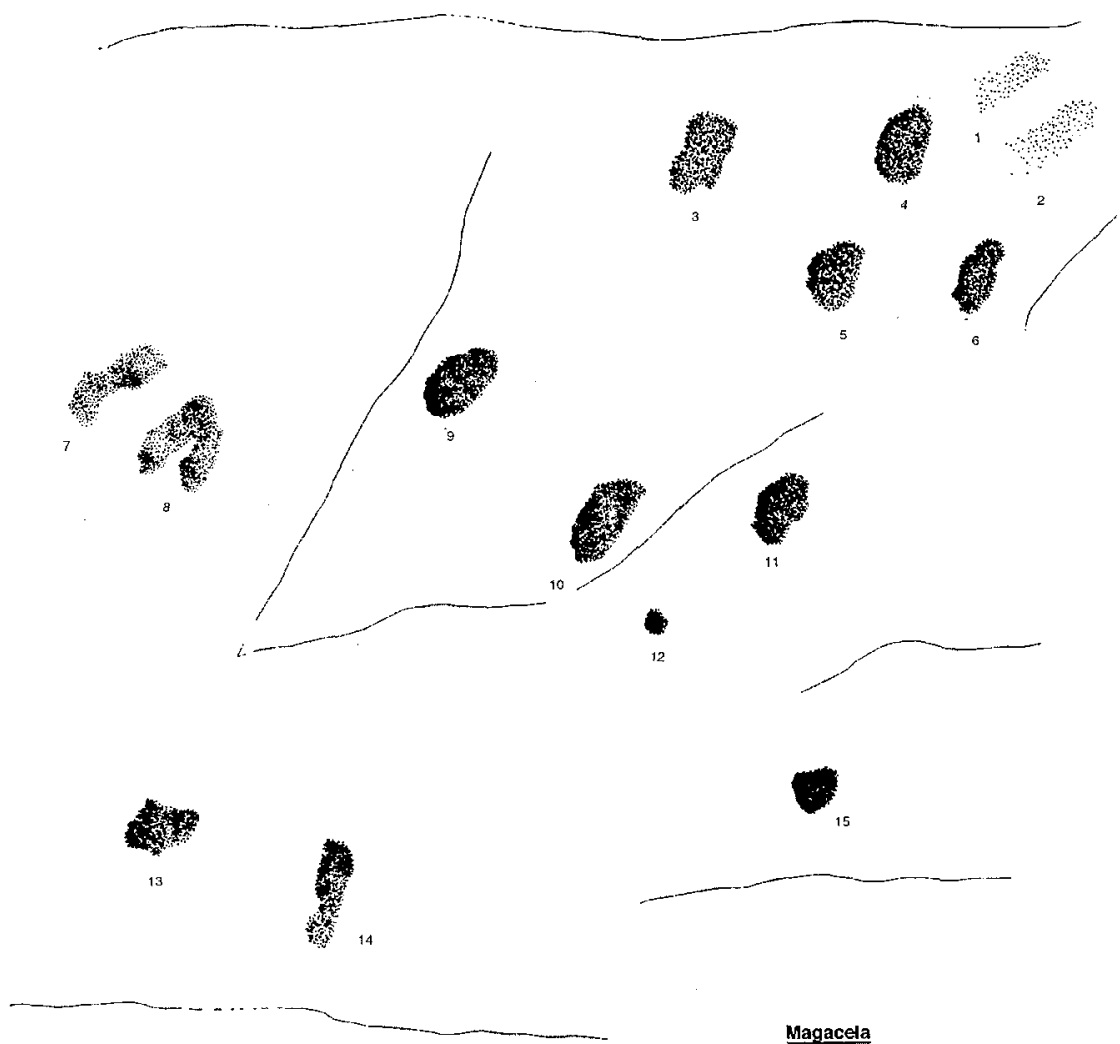

Magaceda

Abrigo B Grupo II

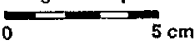

Figura 25. 


\section{ANÁLISIS TIPOLÓGICO}

Los abrigos de la Sierra de Magacela presentan un total de 155 grafemas entre los que podemos apreciar figuras humanas, animales, ídolos, soliformes, ramiformes, zig-zags, barras, puntos, digitaciones, motivos indeterminados e incompletos, estos últimos excluidos a la hora de realizar las estadísticas de porcentualización tipológica con la intención de buscar el máximo de fiabilidad en las mismas. En ellos podemos distinguir tres fases a la hora de realizar las pinturas. La primera cuenta con 62 motivos diferentes, un $40 \%$ del total, hechos en trazo grueso y con una tonalidad rojo clara con tendencia al anaranjado; la segunda sólo aporta 5 figuras, un 3,23\% del conjunto, todas en trazo grueso y color negro, por último, la tercera, es la que cuenta con mayor número de elementos, 88 , un $56,77 \%$ de los motivos representados en el abrigo, realizados en trazo fino y cuidado y con una tonalidad rojo vinosa.

Fase 1

a. Características.

Como hemos dicho anteriormente, son 62 las figuras identificadas para la primera fase pictórica de los abrigos de la sierra de Magacela. De ellos 15 son motivos indeterminados excluidos de las gráficas de porcentajes (cuadro 1). Nos encontramos siempre ante representaciones en tinta plana, monócromas de tonalidad rojo anaranjada, realizadas en trazo grueso usando como aplicador probablemente la yema del dedo (entre $1 \mathrm{~cm}$. y $2 \mathrm{~cm}$. de anchura) y con un tamaño medio que oscila entre los $7 \mathrm{~cm}$. y los $10 \mathrm{~cm}$. de altura. Se disponen sobre pequeñas superficies propiciadas por los cuarteamientos o fracturas del soporte, aisladas e inconexas entre si, no llegando a formar escenas propiamente dichas, todo lo más, asociaciones de figuras como la de tipo ancoriforme-zoomorfo que se repite de forma bastante reiterativa en nuestra estación. 
b. Distribución tipológica

\begin{tabular}{|c|c|c|c|c|}
\hline Antropomorfos & naturalistas & & & \\
\hline & esquemáticos & & 9 & $19,15 \%$ \\
\hline \multirow{2}{*}{ Zoomorfos } & naturalistas & & 3 & $6,38 \%$ \\
\hline & esquemáticos & & 7 & $14,89 \%$ \\
\hline Ídolos & & & & \\
\hline Soliformes & & & 1 & $2,13 \%$ \\
\hline Ramiformes & & & 1 & $2,13 \%$ \\
\hline Zig-Zag & & & & \\
\hline Barras & & & 12 & $25,53 \%$ \\
\hline Puntos & & & 14 & $29,79 \%$ \\
\hline Indeterminados & & & 15 & \\
\hline Incompletos & & & & \\
\hline
\end{tabular}

Cuadro 1

\section{b.1. Antropomorfos (fig. 26).}

Las representaciones antropomorfas en la primera fase de nuestros abrigos son 9, un 19,15\% del total. La mayor parte del tipo ancoriforme, con un eje más o menos axial que forma el tronco y limitadas sólo por la parte superior (fig. 26: 3-5-6-8) o en ambas, superior e inferior (fig. 26: 1 2-4-9), por arcos transversales más o menos abiertos que dan lugar a la cabeza y a las extremidades inferiores. Unicamente en el caso del motivo 7 no se puede asegurar que se trate de un ancoriforme al conservarse sólo el arco transversal inferior.

Las representaciones de ancoriformes son habituales en los abrigos con pintura rupestre esquemática. En Extremadura podemos encontrarlos entre otros, en el abrigo del Puerto de las Ruedas (Peñalsordo) ${ }^{2}$, en el Morro del Valle de la Venta (Cabeza del Buey) ${ }^{3}$, en el abrigo de La Silla (Hornachos) ${ }^{4}$, en los abrigos primero y segundo del Risco de San Blas

2 Breuil H.: Les Peintures rupestres schématiques de la Peninsule lbérique, Vol. II, Bassin du Guadiana, pl. XIX:II.

3 Martinez Perelló, M.l.: «Arte rupestre en Badajoz. Un nuevo abrigo con Pinturas Esquemáticas: El Morro del Valle de la Venta. (Cabeza del Buey)". Revista de Estudios Extremeños, XLIX, n², 1993, p. 309-336.

4 Breull: Les Peintures..., op. cit., pl. XXIX. 

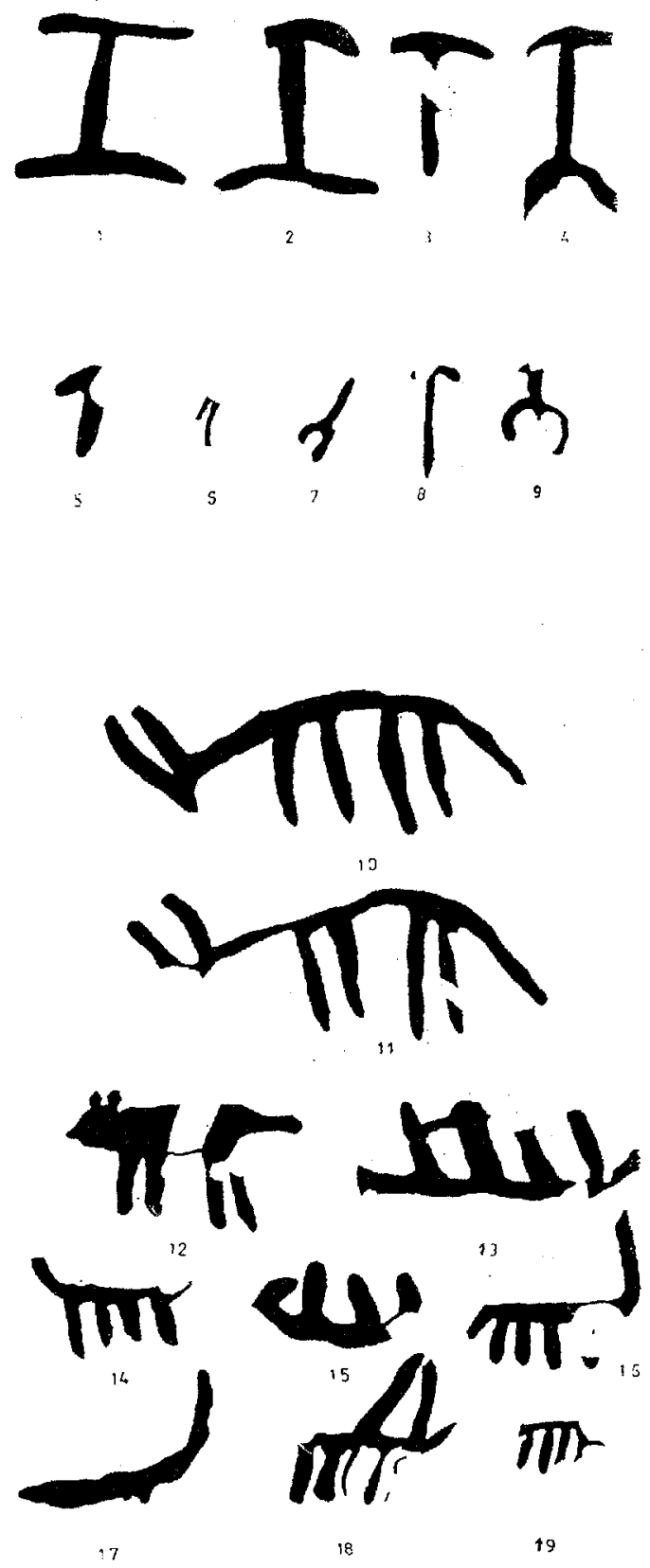

Figura 26. Fase 1: Antropomorfos (1-9), Zoomorfos (10-19). 
(Alburquerque) ${ }^{5}$, y en las estaciones cacereñas de La Madrastra II, el Cancho de la Burra (Cañamero) ${ }^{6}$ y El Buraco (Santiago de Alcántara) 7 .

\section{b.2. Zoomorfos (fig. 26).}

Son diez las representaciones de animales pertenecientes a la primera fase de los abrigos pictóricos de Magacela, un 21,27\% del total. De ellas sólo tres figuras (fig. 26: 10-11-12) presentan ciertos rasgos naturalistas, con clara indicación de la cabeza, cornamentas u orejas, cuerpo, extremidades y rabo. El resto de los motivos presentan un alto grado de esquematismo (fig. 26: 13-19), estando dos de ellos en posición invertida (fig. 26: 13-15) lo que ha sido interpretado como representación del animal ya muerto. En los demás esquemas podemos advertir como se repite la particularidad de un excesivo alargamiento de la zona del cuello (fig. 26: 1416-17-18) lo que nos da pie a pensar en la intervención de una única mano a la hora de plasmar los grafemas sobre la pared.

Las representaciones de animales son muy frecuentes en los abrigos con pintura esquemática de la Península Ibérica, baste recordar los trabajos de Alfonso Caballero ${ }^{8}$, Juan A. Gómez ${ }^{9}$ o Vicente Baldellou ${ }^{10}$ entre otros. En Extremadura los paralelos son tambien numerosos, por destacar algunos citaremos el abrigo del Valle de la Huerta Vieja (Peñalsordo) ${ }^{11}$, abrigo $n^{\circ} 1$ de la Sierra de la Panda (Talarrubias) ${ }^{12}$, abrigo $n^{\circ} 8$ de la Sierra de San Serván (Arroyo de San Serván) ${ }^{13}$, abrigo ${ }^{\circ} 1$ del Risco de

5 BREUIL: Les Peintures..., op. cit., pl. XXXIX.

- Garíía ARRanz, J.J.: «Las representaciones humanas en la Pintura Rupestre Esquemática de la provincia de Caceres: Tipología y distribución geográfica». Actas de los XIX Coloquios Históricos de Extremadura, Trujillo, 1990, p. 145-163.

7 Amador Carretero, P. et alii: «Pinturas Esquemáticas inéditas de «El Buraco» (Santiago de Alcántara)». Actas del VI Congreso de Estudios Extremeños, Mérida, 1979, p. 16-32.

- Caballero Klink, A.: La Pintura Rupestre Esquemática de la vertiente septentrional de Sierra Morena (Ciudad Real) y su contexto arqueológico, Estudios y monografías del Museo de Ciudad Real, n'9, 1983 , p. 466-473.

9 Gómez BARRERA, J.A.: La Pintura Rupestre Esquemática en la altimeseta soriana, Publicaciones del Excmo. Ayuntamiento de Soria, Soria, 1982, p. 199-207.

10 Baldellou, V.: «El arte rupestre post-paleolítico de fa zona del río Vero (Huesca)», Ars Prehistórica, III-IV, 1984-85, p. 111-137.

11 Martínez Perelló, M.l.: «Un nuevo conjunto de Pinturas Esquemáticas en la Sierra del Pedroso (Peñalsordo y Capilla, Badajoz), Ars Prehistórica, VII-VIII, 1988-89, p. 201-219.

12 Gavilán Ceballos, B. y Vaquerizo GIL, D.: "Un nuevo conjunto de Pinturas Rupestres en la provincia de Badajoz: Las cuevas de la Panda (Talarrubias)", Ifigea, V-VI, 1988-89, p. 9-34.

13 Ortiz Macías, M. y Muñoz-Torrero Cabal.lero, E.: «Pinturas Rupestres Esquemáticas: escenas y composiciones. Arroyo de San Serván, Mérida y Zarza de Alange (Badajoz), Revista de Estudios Extremeños, XLVI, 1990, p. 87-111. 
San Blas (Alburquerque) ${ }^{14}$, Cancho de la Burra (Cañamero), Cancho del Reloj (Cabañas del Castillo) y abrigo de la Madrasta II (Cañamero) ${ }^{15}$.

\section{b.3. Soliforme (fig. 27).}

Es la única figura de este tipo que hemos hallado en el abrigo que estamos estudiando, suponiendo a la hora de evaluar los porcentajes de distribución únicamente un $2,13 \%$ del total de las representaciones de esta primera fase (fig. 27: 1).

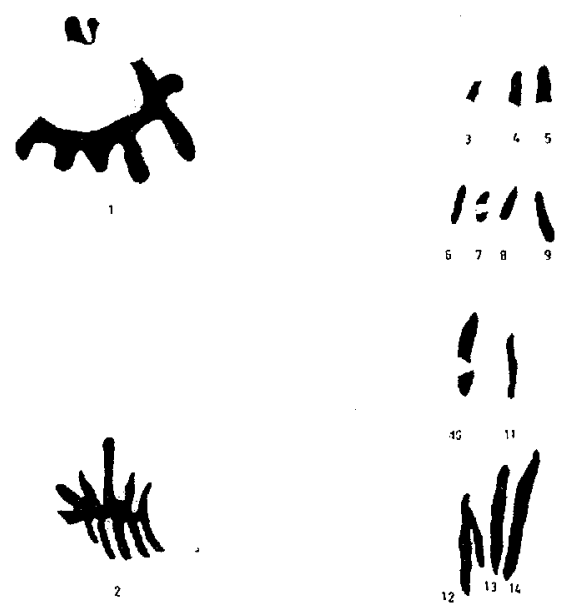

Figura 27. Fase 1: Soliforme (1), Ramiforme (2), Barras y digitaciones (3-14).

Al igual que sucedia con los motivos antropomorfos y zoomorfos, los soliformes se hallan distribuídos en los más variados abrigos a todo lo largo y ancho de la geografía peninsular. En nuestra región son tambien numerosos las estaciones con este tipo de figuración sobre sus paredes destacando entre otros los abrigos $n^{\circ} 1$ y 3 de El Montón (Helechal), el abrigo $n^{\circ} 5$ de «Las Moriscas» (Helechal), los $n^{\circ} 1$ y 9 de «Los Buitres» (Peñalsordo), en la Gruta de la Sierra de los Agallares (Peñalsordo) ${ }^{16}$,

\footnotetext{
14 HERnÁNDEZ-PACHECO, E.: “Pinturas prehistóricas y dólmenes de la región de Alburquerque", Boletin de la Real Sociedad Española de Historia Natural, XVI, 1916, p. 118-128.

15 García ArRAnZ, J.J.: «Los animales en la pintura rupestre esquemática de las villuercas (Caceres): testimonio gráfico de un modo de vida prehistórico", Alcántara, n ${ }^{\circ} 20,1990$, p. $89-110$.

16 Martinez Perelló, M.l.: La Pintura rupestre esquemática en la zona oriental de la provincia de Badajoz: estado de la cuestión", Espacio, Tiempo y Forma, Serie 1, 6, 1993, p. 97-132.
} 
abrigo $n^{\circ} 10$ de la Sierra de San Serván (Arroyo de San Serván) ${ }^{17}$ y el $n^{\circ}$ 8 de la misma sierra ${ }^{18}$, en el Cancho del Reloj (Cabañas del Castillo), en la Cueva de la Era del Gato (Cabañas del Castillo) y en el Cancho de la Burra (Cañamero) ${ }^{19}$.

\section{b.4. Ramiforme (fig. 27).}

Al igual que sucedía con el soliforme, ésta es la única figura de esta tipología que aparece en la primera fase pictórica de los abrigos de Magacela, lo que supone porcentualmente un $2,13 \%$ del total de los motivos del período inicial (fig. 27: 2). Hemos decidido interpretar esta figura como ramiforme, a pesar de estar en posición horizontal y poder tomarla como una representación animalística, porque, como hemos visto con anterioridad, los motivos zoomorfos de este primer momento repiten con cierta asiduidad los mismos convencionalismos y el grafema que estamos analizando se desliga totalmente de los mismos. Tampoco me parece acertada aplicarle la interpretación que Miguel Soria obtiene a partir de la escena localizada en la Cueva del Plato (Granada) ${ }^{20}$, donde considera estos motivos como agrupaciones de barras unidas por un trazo transversal con un probable fin enumerativo, considerando las barras como esquematizaciones de seres humanos.

Motivos similares encontramos en los abrigo $n^{\circ} 5$ y 10 de los Buitres (Peñalsordo) ${ }^{21}$, en la Sierra de Arroyo de San Serván ${ }^{22}$, en la Grajas (Helechal) ${ }^{23}$, La Grajera (Torremegía) ${ }^{24}$, abrigos $n^{\circ} 1$ y 2 del Peñón del Pez, Gruta de los Agallares, abrigo $n^{\circ} 1$ del Valle de la Huerta Vieja (Peñalsordo) ${ }^{25}$ y Cancho del Reloj (Cabañas del Castillo) ${ }^{26}$.

17 Ortiz Macías, M. y Muñoz-Torrero Caballero, E.: «Dos estaciones de Pinturas Rupestres Esquemáticas en la sierra de San Serván (Badajoz)», Actas del XIX Congreso Nacional de Arqueología, II, Zaragoza, 1989, p. 249-258.

18 Ortiz Macias y Muñoz-Torrero Caballero: «Pinturas rupestres esquemáticas...», op. cit., p. $91-92$.

19 García Arranz, J.J.: La Pintura Rupestre Esquemática en a comarca de las Villuercas (Cáceres), Diputación Provincial de Caceres, Institución cultural «El Brocense», Caceres, 1990, p. 193-195.

20 SORIA Lerma, M.: La pintura rupestre en el Sureste de la Península Ibérica, Universidad Complutense, Madrid, 1988, p. 117-120.

${ }_{21}$ BREUIL: Les Peintures..., op. cit., vol. II, pl. XVI y XVIII.

22 BreulL: Les Peintures..., op. cit., vol. Il, pl. XXXVII.

23 BreulL: Les Peintures..., op. cit., vol. II, fig. 31.

24 BREUIL: Les Peintures..., op. cit., vol. II, fig. 27.

25 Martínez Perelló: «Un nuevo conjunto...», op. cit., p. 201-219.

26 García Arranz: La Pintura Rupestre..., op. cit., p. 67-6. 
b.5. Barras y puntos (fig. 27 y fig. 31 ).

Son catorce los grafemas del formato barra que se pueden observar en los abrigos de la Sierra de Magacela, o sea un 25,53\% del total de las figuras de la primera fase (fig. 27). Aparecen en la mayor parte de los casos de forma individual, contando únicamente con un agrupamiento de tres (fig. 27: 12-14) en posición vertical. Es difícil dar significado a estos motivos ya sea de forma individual o colectiva pues suponen el culmen del proceso de abstracción a que se ha visto sometida la figura original. Descartamos, en nuestro caso, unos incipientes sistemas de contabilidad, y tampoco podríamos atribuirles con seguridad un significado antropomórfico como advierte Pilar Acosta en algunas ocasiones ${ }^{27}$, asociados a veces, a escenas consideradas como rituales funerarios ${ }^{28}$. Teógenes Ortego aúna en el «abrigo del Tubo» los motivos barra a una escena que considera también como la plasmación de un enterramiento ${ }^{29}$. En nuestro caso, sólo el motivo 12 (fig. 27: 12) podría ser considerada con muchas reservas, en función del apéndice lateral que presenta a modo de brazo o de objeto portado, como la representación de un antropomorfo.

Los puntos, a pesar de localizarse en agrupaciones, han sido tomados como elementos individuales. Suponen un total de catorce motivos, un $29,79 \%$ de las representaciones recogidas (fig. 31: fase 1), lo que hace de ellos el tema más reiterado de los representados en Magacela. Su interpretación, al igual que sucedía con las barras, resulta totalmente incierta; desde esquemas constructivos hasta piedras (entendidas como armas arrojadizas) ${ }^{30}$, significaciones simbólicas ${ }^{31}$ o sistemas de contabilidad ${ }^{32}$, esta última, es la interpretación que mejor se puede aplicar a la agrupación número nueve del abrigo (fig. 14), formada por dos hiladas paralelas de cuatro y nueve puntos respectivamente.

Las representaciones de barras y puntos aparecen en la práctica totalidad de los abrigos con pintura esquemática no sólo de la región, sino de toda la geografía peninsular. Por citar algunos ejemplos localizados en

27 Acosta: La Pintura Rupestre..., op. cit., p. 115.

28 Acosta: La Pintura Rupestre..., op. cit., p. 164-166

29 Ortego frías, T.: «Las pinturas rupestres del Peñón de la Sendilla, en el Monte Valosandero de Soria», Boletín de la Asociación Española de Amigos de la Arqueología, $\mathrm{n}^{\circ} 1$, 1974 , p. 12.

30 Ortego Frias, T.: «Nuevos hallazgos de arte rupestre en el alto Duero", Zephyrus, V, 1954, p. 26.

31 BREUIL, H. y BURKITT, M.: Rock paintgings of Southern Andalusia, Oxford, 1929, p. 68.

32 Acosta: La Pintura Rupestre..., op. cit., p. 113. 
Extremadura nombraremos el abrigo $n^{\circ} 1$ del Peñón del Pez (Capilla) ${ }^{33}$, abrigos 2, 5 y 8 de Los Buitres (Peñalsordo) ${ }^{34}$, abrigo $n^{\circ} 1$ de la Sierra de San Serván (Arroyo de San Serván) ${ }^{35}$, Cueva Chiquita (Cañamero) y el Cancho del Reloj (Solana) ${ }^{36}$.

b.6. Motivos incompletos (fig. 29).

Nos encontramos en la totalidad de los casos, como puede observarse en la figura 29, con restos de figuras, grafemas incompletos o restos de pigmentación, todos muy degradados por la acción de los diversos agentes erosivos (antrópicos o no) lo que hace prácticamente imposible su clasificación tipológica. Esta indefinición es la que ha provocado su exclusión de las tablas porcentuales de distribución de motivos, tratando, de este modo, evitar falseamientos a la hora de analizar estos porcentajes.

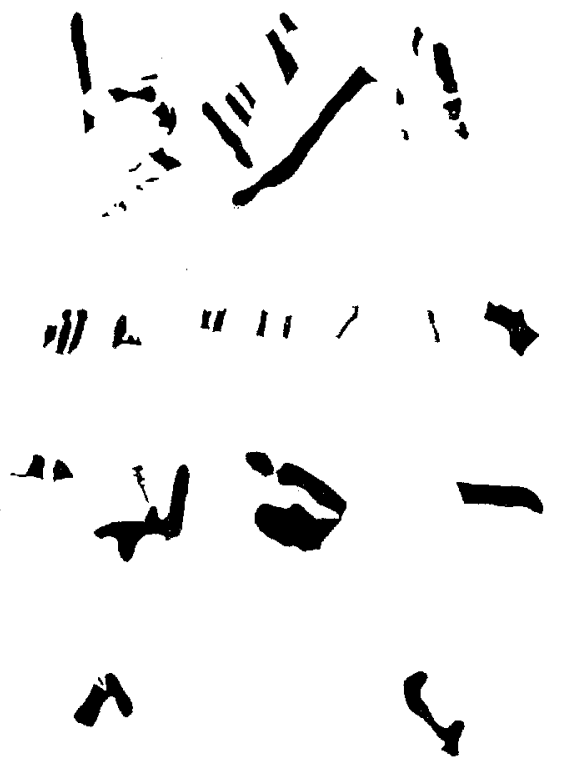

Figura 29. Fase 1: Motivos incompletos.

33 Martínez Perelló: «Un nuevo conjunto...», op. cit., p. 205.
34 Breull: Les Peintures..., op. cit., vol. II, pls. XV y XVII.
35 Acosta: La Pintura Rupestre..., op. cit., p. 114, fig. 31 : 1-6.
36 García ARranz: La Pintura Rupestre..., op. cit., p. 74 y 150. 


\section{Fase 2}

\section{a. Características}

En esta segunda fase, establecida en función de la superposición de grafemas del grupo $X$ (fig. 15: 2-3), nos vamos a encontrar únicamente con 5 motivos de unas características y un grado de esquematización similares al período anterior en lo referente al estilo, tipología, grosor del trazo, tamaño de las figuras y distribución sobre el soporte. La novedad viene introducida por la tonalidad empleada en todas las representaciones (el negro) y por la aparición de un nuevo tipo de motivo que no se da en la fase anterior: un ídolo oculado.

b. Distribución tipológica

\begin{tabular}{|c|c|c|c|c|}
\hline Antropomorfos & naturalistas & & & \\
\hline & esquemáticos & & 3 & $60 \%$ \\
\hline Zoomorfos & naturalistas & & & \\
\hline & esquemáticos & & & \\
\hline Ídolos & & & 1 & $20 \%$ \\
\hline Soliformes & & & & \\
\hline Ramiformes & & & & \\
\hline Zig-Zag & & & & \\
\hline Barras & & & & \\
\hline Puntos & & & 1 & $20 \%$ \\
\hline Indeterminados & & & & \\
\hline Incompletos & & & & \\
\hline
\end{tabular}

Cuadro 2

\section{b.1. Antropomorfos (fig. 30).}

Son los esquemas más reiterados de esta fase, contabilizandose 3 representaciones del tipo ancoriforme que suponen un $60 \%$ del total de las figuraciones de este período (fig. 30: 1-2-3). Presentan una barra vertical sobre la que se dispone un arco transversal más o menos curvado, estando solamente uno de los motivos incompleto al haber perdido la parte izquierda de la barra transversal superior (fig. 30: 1). Su área de distribución en Extremadura es similar a la citada con anterioridad para los ancoriformes de la primera fase. 

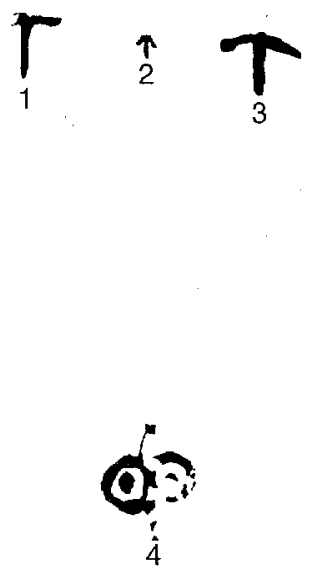

Figura 30. Fase 2: Antropomorfos (1-3), Idolo (4).

b.2.- Punto (fig. 31).

Hallamos un único punto, localizado en la parte inferior derecha del grupo XVI (fig. 18: 5), constituyendo un $20 \%$ del total de las representaciones contabilizadas en esta segunda fase.

\section{b.3.- Idolo (fig. 30).}

Esta última figura supone el $20 \%$ restante del total de los grafemas plasmados en el segundo período de nuestra estación pictórica. Es excepcional la aparición de este motivo, un ídolo oculado, tanto por su fisonomía, al redondear los arcos superciliares cerrándolos bajo los ojos hasta completar el círculo (fig. 30: 4), algo que parece corresponder más a la zona de Sierra Morena que a la extremeña, donde las representaciones de ídolos oculados marcan de forma ostentosa los arcos superciliares, restando importancia a las líneas bajo los ojos ${ }^{37}$, como por el color con que ha sido plasmado sobre la

37 AcostA, P.: «Representaciones de ídolos en la Pintura Rupestre Esquemática española», Trabajos de Prehistoria, 24, 1967, p. 29. 
000

$\bullet \bullet \bullet \bullet \bullet \bullet \bullet \bullet \bullet$

Fase 1

Fase 2

9

00

8

00

$\infty 0+.1044 \cdots$

Fase 3

Figura 31. Puntos. 
pared: el negro, lo que singulariza nuestro ídolo no sólo respecto al resto de ídolos oculados localizados en los abrigos extremeños, sino tambien respecto a los demás ídolos oculados representados en los abrigos de la Península Ibérica en una amplísima gama cromática de ocres y rojos.

En Extremadura los paralelos más próximos los encontramos todos en la provincia de Badajoz, en el abrigo $\mathrm{n}^{\circ} 2$ de la Majadilla de Puerto Alonzo (Cabeza del Buey) ${ }^{38}$, en el $n^{\circ} 3$ de la Sierra de San Serván (Arroyo de San Serván) ${ }^{39}$, en los números 1 y 10 de los Buitres (Peñalsordo) ${ }^{40}$ y en el abrigo pequeño de la Viñas (Zarza de Alange) ${ }^{41}$.

Fase 3

a. Características

Esta última fase pictórica de Magacela es la que aporta mayor número de motivos, 78 identificados, más otros 10 indeterminados, constituyendo además, un sustancial cambio con respecto a las fases precedentes tanto en técnica como en estilo y con una clara superposición de motivos de este período sobre dos representaciones zoomorfas de la primera fase (grupo IV). En este momento el autor sí va a preocuparse por la disposición y distribución de las figuras en espacios de pared amplios con la intención de componer escena. Surge el deseo de jerarquización, figuras de las mismas características aparecen en tamaños diferentes y con colocaciones prioritarias para las de mayor tamaño. Técnicamente se impone el uso del trazo fino y cuidado y el gusto por el detalle, plasmando las figuras en tonalidades rojo vinosas muy marcadas. Por último, el estilo naturalista se adueña de las figuras frente al esquematismo imperante de fases anteriores.

\footnotetext{
38 BREUIL: Les Peintures..., op. cit., vol. II, pl. XXIV.

39 Breull: Les Peintures..., op. cit., vol. II, pl. XXXII.

40 BREUIL: Les Peintures..., op. cit., vol. II, pls. XIII XIV-XVIII.

41 BREUIL: Les Peintures..., op. cit., vol. II, pl. XXXI.
} 
b. Distibución tripológica.

\begin{tabular}{|c|c|c|c|c|}
\hline Antropomorfos & naturalistas & & 14 & $17,95 \%$ \\
\hline & $\begin{array}{c}\text { esquemáticos } \\
\text { Zoomorfos }\end{array}$ & & & \\
\hline & naturalistas & & 4 & $5,13 \%$ \\
\hline édolos & & & & \\
\hline Soliformes & & & & \\
\hline Digitaciones & & & & \\
\hline Zig-Zag & & & 6 & $7,69 \%$ \\
\hline Barras & & & 1 & $1,28 \%$ \\
\hline Puntos & & & 7 & $8,97 \%$ \\
\hline Indeterminados & & & 43 & $55,13 \%$ \\
\hline Incompletos & & & 3 & $3,85 \%$ \\
\hline
\end{tabular}

Cuadro 3

\section{b.1. Antropomorfos (fig. 32).}

Tras los puntos, son la tipología de figuras más numerosas de este período, contabilizando 14 motivos, lo que supone un $17,95 \%$ del total de las figuras. Excepto el motivo 11 (fig. 32: 11) todas presentan características similares: cabeza y tronco alargados, piernas abiertas y brazos superpuestos. Hay un intento por parte del autor de romper con la tradicional frontalidad y el hieratismo predominantes en la pintura rupestre esquemática. Busca la perspectiva lateral, de ahí que los brazos aparezcan superpuestos y consigue dar movimiento a las figuras, flexionando la pierna trasera y levantando la delantera (fig. 32: 2- 4- 5-6) o acortando la pierna de atrás y alargando la de delante (fig. 32: 1-9).

La diferenciación sexual sólo se da en el motivo 11 y en el 14, en los que el falo aparece bien marcado, el resto de las figuras aparecen asexuadas sin poder definir con seguridad si se trata de motivos masculinos o femeninos, salvo en el caso del motivo 13 (una mujer), que aparece junto al 14 (un hombre), formando pareja. Ella se diferencia del varón en el tratamiento de la cabeza, más redondeada y representando la nariz o el mentón, y por las caderas, que aparecen bien marcadas. A su vez estas dos figuras se jerarquizan del resto en función de su mayor tamaño y su posición privilegiada en lo alto del panel. Por último, el detallismo con el que han sido representados los motivos permite apreciar elementos de carácter etnográfico tales como los tocados de las representaciones 1 y 


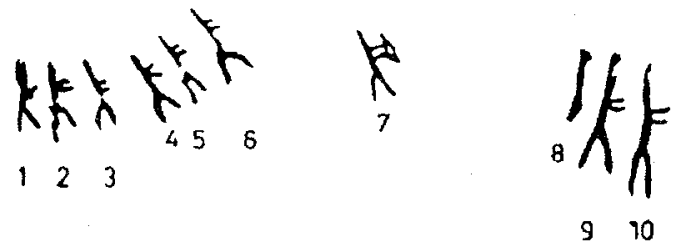

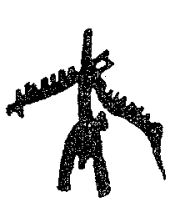

19

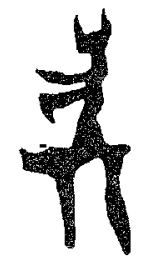

12

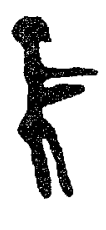

13

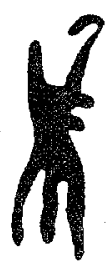

16

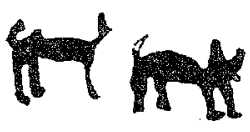

$15 \quad 16$

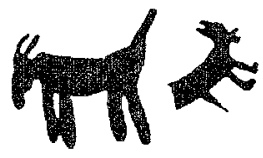

$17 \quad 18$

Figura 32. Fase 3: Antropomorfos (1-14), Zoomorfos (15-18). 
12, el primero posiblemente un par de plumas ornamentales y el segundo un casco con cuernos similar al que porta el guerrero representado en la estela de Magacela ${ }^{42}$, adornos relacionados con el ropaje, como podemos observar en el motivo 11, en la que una especie de plumas o flecos se distribuyen a lo largo de las dos mangas, o armas, como el arco portado por el motivo 7, o el bastón que sostiene entre sus manos el motivo 14.

Las características de estas figuras los singularizan con respecto a otros motivos antropomorfos representados en Extremadura, donde sólo un antropomorfo localizado en el Cancho de la Burra ${ }^{43}$, con una disposición de sus extremidades superiores que nos hace recordar vagamente a las de los plasmados en los abrigos de Magacela. Así pues, los paralelos con otras estaciones de arte esquemático unicamente los podremos establecer en función de los objetos portados por los personajes, como el arco que lleva entre sus manos el motivo 7 (fig. 32: 7) y que puede ser comparada con el arquero del abrigo pequeño del puerto de Malas Cabras ${ }^{44} \mathrm{O}$ con el localizado y discutido arquero de la Cueva del Castillo de Montfragüe ${ }^{45}$, o el casco de cuernos representado en el motivo 12 (fig. 32 : 12) cuyos paralelos más próximos dentro de la pintura rupestre esquemática extremeña se localizan en el abrigo $n^{\circ} 1$ del Peñón del pez ${ }^{46}$ y en el abrigo pequeño del puerto de Malas Cabras ${ }^{47}$.

\section{b.2. Zoomorfos (fig. 32).}

Unicamente contamos con cuatro representaciones de animales, un 5,13 $\%$ del total de los motivos de este período. Al igual que sucedía con los antropomorfos, han sido plasmados de forma minuciosa, empleando el trazo fino y marcando con detalle las diferentes parte anatómicas del animal (orejas, hocicos, pezuñas, rabos, cuernos). Así, en función de las características

42 Enriquez, J.J. y Hurtado, V.: Historia de la Baja Extremadura, vol. I. Prehistoria y Protohistoria, Real Academia de Extremadura de la Letras y las Artes, Badajoz, 1986, p. 61.

43 García ARRAnz, J.J.: "Las representaciones humanas en la pintura rupestre esquemática de la provincia de Cáceres: Tipología y distribución geográfica", Actas de los XIX Coloquios históricos de Extremadura, Trujillo, 1990, p. 160, lám. VIII, fig. 19.

44 BreulL: Les Peintures..., op. cit., vol. Il, pl. XXXV.

45 GaRcia MOgOLLón, F.J.: «Las pinturas esquemáticas del Montfragüe, en la provincia de Caceres", Revista de Estudios Extremeños, XXX, 1974, p. 551-580; BELTRÁN Lloris, M.: “Las pinturas rupestres esquemáticas del castillo de Montfragüe en Torrejón el Rubio (Caceres)", Estudios de arqueología cacereña, Zaragoza, 1973, p. 59-85.

46 Martinez Perello: "Un ifuevo conjunto...", op. cit., p. 205.

47 Acosta: La Pintura Rupestre..., op. cit., p. 146, fig. 6. 
somáticas de los mismos podemos distinguir tres perros (fig. 32: 15-16-18) con las orejas y el hocico bien definidos al igual que las patas,(similares en las tres figuras) y la cola levantada y curva. El motivo 17 lo identificamos con una cabra, siendo sus características diferentes a la de los perros: hocico más alargado, cola sin curvar y pezuñas sin marcar. Todos estos animales aparecen de forma más o menos aislada exceptuando el motivo 16, que se asocia ciaramente a un antropomorfo (fig. 5: 1-2). El animal aparece representado unido al hombre a la altura de su mano como si estuviera tomando algo que el hombre le ofrece en un gesto evidente de docilidad hacia su dueño.

Al contrario de lo que sucedia con los motivos antropomorfos, para las figuras zoomorfas de los abrigos de Magacela si encontramos numerosos paralelos como los existentes en la Cueva de los perros (Zarza Capilla) ${ }^{48}$, La Atalaya (Alange) ${ }^{49}$, Cancho de la Burra (Cañamero) y Abrigo II de la Sierra de la Madrastra (Cañamero) ${ }^{50}$.

\section{b.3. Zig-zag (fig. 33).}

Localizamos un único motivo de estas características en el abrigo $\mathrm{n}^{\circ}$ 1 de Magacela (fig. 33: 3), lo que supone un 1,28\% del total de las figuras representadas. Está trazado en línea gruesa y relativamente aislado con respecto a! resto de las figuras de su grupo (grupo V). Su relación más directa se establecería con una serie de motivos actualmente incompletos (fig. 9: 3-4-5-6) que no ayudan a clarificar su significado, siendo imposible darles una interpretación antropomórfica tal y como lo hace Breuil con los zig-zag de Minateda ${ }^{51}$ o la Peña Escrita de Fuencaliente ${ }^{52}$.

En Extremadura encontramos paralelos en el Abrigo $n^{\circ} 1$ del Peñón del Pez ${ }^{53}$ (Capilla), en el abrigo $n^{\circ} 10$ de los Buitres (Peñalsordo) ${ }^{54}$ y en el abrigo de la Sirenita (Serradilla) ${ }^{55}$.

48 GonzÁlez, J.A. y GuTIÉRREZ, J.A.: «Aportaciones al conocimiento de la pintura esquemática en Extremadura», Revista de Estudios Extremeños, XLVIII, 1992, p. 153-199.

49 Breull: Les Peintures..., op. cit., vol. II, pl. XXXV. Ile.

50 García ArRanz: «Los animales en la pintura...", op. cit., p. 89-110.

51 BREUIL: y BURKITT: Rock paintings..., op. cit., p. 7-8, fig. 7.

52 Breuil: Les Peintures..., op. cit., vol. III, p. 84, pls. XLV y XLVI.

53 Martínez Perelló: «Un nuevo conjunto...», op. cit., p. 206.

54 BREUIL: Les Peintures..., op. cit., vol. II, pl. XVIII.

55 Rubio Andrada, M.: La pintura rupestre en el parque natural de Monfragüe (Caceres), Trujillo, 1991, p. 71-74. 


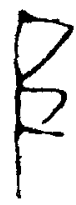

1
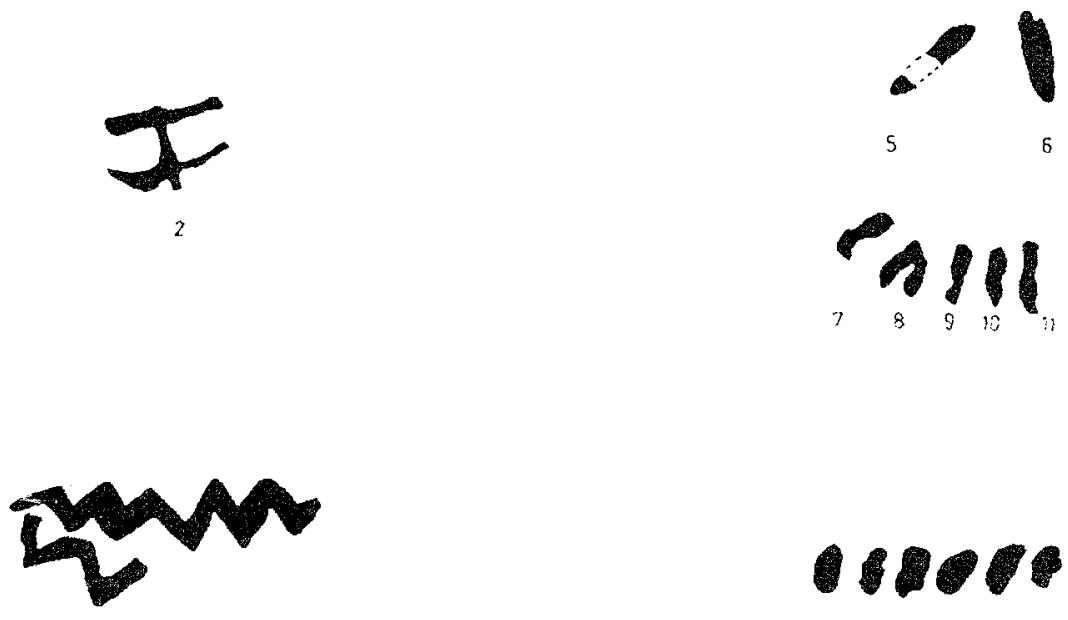

3

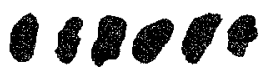

$\begin{array}{llllll}12 & 13 & 14 & 15 & 15 & 17\end{array}$

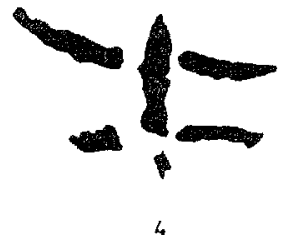

Figura 33. Fase 3: Indeterminados (1, 2, 4), Zig-zag (3), Barras y digitaciones (5-17). 
b.4. Barras, puntos y digitaciones (fig. 33).

Unicamente se localizan siete barras (fig. $33: 5$ a 11), que suponen un $8,97 \%$ del total de las figuras analizadas en esta última fase. En nuestro caso es muy difícil optar por algún tipo de interpretación, máxime cuando estos grafemas no aparecen asociados de forma clara a ningún otro motivo y tampoco presentan ningún tipo de indicación mediante la cual pudiera atribuirseles un carácter antropomórfico o etnográfico.

Por contra, los puntos son el tema más reiterado de este tercer período, apareciendo definido claramente en 53 ocasiones, lo que supone un $55,13 \%$ del total de las figuras. En la mayor parte de los casos aparecen de forma conjunta estableciendo alineaciones horizontales o verticales (fig. 31: fase 3). Sus posibles interpretaciones ya fueron analizadas en el apartado dedicado al estudio de los grafemas punto de la primera fase, aunque en esta tercera fase habría que destacar una alineación de diez puntos en horizontal asociados de forma clara a una figura humana (grupo $V$ ) y que podrían ser considerados como el rastro de algún animal (sangre, huellas, etc.) que está siendo seguido por el cazador.

Por último son seis las digitaciones localizadas en los abrigos de Magacela, el 7,69 \% de los motivos representados. Se diferencian de las barras por su menor longitud, en torno a los $3 \mathrm{~cm}$. de media y por su mayor grosor, $1,5 \mathrm{~cm}$. y de la misma manera las digitaciones tambien se presentan de forma aislada, sin establecer ningún tipo de asociación con otros motivos (fig. 33: 12 a 17).

\section{b.5. Motivos indeterminados (fig. 33).}

En este apartado hemos incluido tres motivos, que a pesar de conservarse completos nos ha sido imposible darles una significación coherente constituyendo sólo un 3,85\% del total de las representaciones (fig. 33: 12-4). Grafemas similares al motivo 2 y al 4 han sido considerados como ramiformes simples por Alfonso Caballero ${ }^{56}$ otorgandoles un valor antropomórfico. José Julio García ${ }^{57}$, opta por interpretarlos como cruciformes dobles y tambien podrían ser tomados como figuras en doble $Y$ con una aberłura excesiva de los apéndices superiores e inferiores.

\footnotetext{
56 Caballeno Klink: La pintura rupestre esquemática en la vertiente..., op. cit., p. 454-455, lám. 6, figss. 1, 2, 3 .

57 Garcia ArRanz: «Las representaciones humanas...», op. cit., p. 149, lám. II.
} 
El motivo 1 (fig. 33: 1) supone una novedad en el conjunto de la pintura esquemática extremeña y con muchas reservas es posible que pudiera tratarse, dadas sus características estilísticas y su singularidad, de algún tipo de grafía propia de un alfabeto indígena, aunque sin descartar posibles paralelos, teniendo en cuenta que la motivación sería totalmente diferente, en los grabados y pinturas de algunos dólmenes peninsulares.

b.6. Motivos incompletos (fig. 34).

Al igual que sucedía en la fase 1, nos encontramos tambien en este tercer período con diez motivos (fig. 34) que han llegado hasta nosotros de un modo fragmentario, a causa de su lamentable estado de conservación, no pudiendo ser incluidos en ninguna clasificación tipológica ni en tablas de porcentualización con el fin de obtener datos con el menor margen de falseamiento posible.
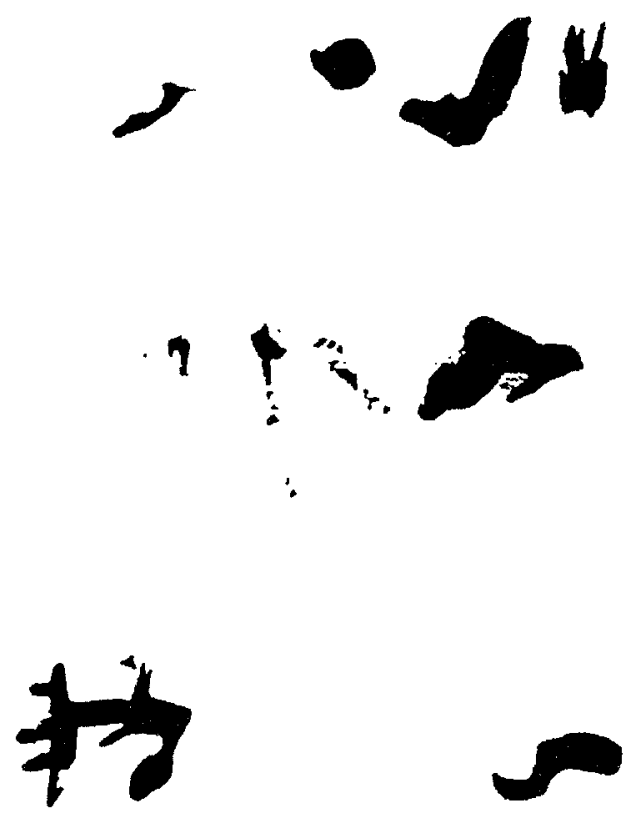

Figura 34. Fase 3: Motivos incompletos. 


\section{CONCLUSIONES.}

La investigación tradicional del arte esquemático cayó en el error de considerar a este estilo pictórico como un fenomeno homogeneizador para la práctica totalidad del territorio peninsular, basándose para ello en la tambien relativa homogeneidad formal de la pintura rupestre esquemática. Al tomar solamente este «unicum» como referencia, se pasaba por alto una realidad importantísima: el arte es producto de la sociedad que lo produce, una sociedad cuyos preceptos culturales, sociales y religiosos, van a evolucionar con el paso del tiempo. Es lógico pensar que el arte, tomado como medio de expresión y comunicación válido para transmitir ideas, bien sean materiales o espirituales, sufra la misma evolución aunque se mantengan, en mayor o menor medida, similares medios de expresión artística con el transcurrir de los siglos.

Con este precedente pasaremos a analizar la evolución que sufre la pintura rupestre esquemática de los abrigos de Magacela en base a las tres fases o periodos que en ellos hemos podido establecer a partir de las superposiciones de motivos y a los distintos colores y tonalidades con que fueron plasmadas estas pinturas en cada momento.

Observando los gráficos (cuadro 1), podemos comprobar que en la primera fase del abrigo $n^{\circ} 1$ los motivos de tonalidad rojo anaranjado, son de alto contenido esquemático (antropomorfos, zoomorfos, soliformes, ramiformes, puntos, barras, prácticamente sin ninguna concesión al naturalismo), exceptuando los motivos 10, 11, y 12 de la fig. 26, (las dos primeras pertenecen al grupo IV y la tercera al VIII). Su autor busca pequeñas superficies proporcionadas por los cuarteamientos de la roca para disponer sus grafemas. Nunca compone escena, todo lo más, asocia motivos tipo como la unión antropomorfo-zoomorfo (que se repite en los grupos VI, XIII y XIX), conjuntos de puntos (grupo IX) o agrupaciones de barras (grupo XVII). El tamaño de las figuras es muy regular, oscilando entre los $7 \mathrm{~cm}$. y los $10 \mathrm{~cm}$., estando todas realizadas con trazo grueso. La persona que plasmó estos grafemas en ningún momento trató de establecer o transmitir con sus dibujos idea o concepto de jerarquización. Todas las figuras humanas, animales y esquemáticas, presentan similar escala, sin destacar ninguna por encima de otra. Se nos reflejan, mediante estos esquemas, elementos propios de una sociedad igualitaria, comunal, con una clara dependencia de los animales, ya sean los domésticos, o los proporcionados por la caza. En este sentido vimos en el gráfico (cuadro I) como los porcentajes de figuras humanas y de figuras animales son similares, a lo que hay que añadir las asociaciones hombre-animal citadas con anterioridad. Todos estos rasgos nos conducen 
a una sociedad de corte neolitizante donde prima la idea del común sobre el individuo y en la que la dependencia respecto a los animales es aún prácticamente total.

La segunda fase, establecida en función de la superposición del motivo 3 sobre el 2 en el grupo $X$, mantiene los mismos rasgos estilísticos que la anterior en lo referente a tamaño de las figuras, grado de esquematismo y disposición de los grafemas sobre el soporte. La novedad viene introducida por el uso exclusivo del color negro a la hora de plasmar los esquemas sobre la roca y sobre todo, por la aparición de una nueva figura inexistente tanto en la fase anterior como en la posterior. Se trata de un ídolo oculado, localizado en el grupo VI (fig. 11: 9) y que viene a indicar la asunción por parte de las gentes autoras de estas pinturas, de nuevas ideas y conceptos sociales y religiosos llegados del mundo mediterráneo. Como bien advierte Pilar Acosta, el calcolítico revitaliza y potencia el viejo sustrato artístico neolítico añadiéndole nuevos temas, reflejo de su fecundo arte mueble ${ }^{58}$. De la tradición indígena precedente permanecen las representaciones antropomórficas que encontramos en los grupos VIl y $\mathrm{X}$, similares en todas sus características a los antropomorfos de la primera fase. El ídolo supone ese aire nuevo y revitalizador que la importada tradición calcolítica impone a la pintura esquemática de raigambre indígena ya presente en la fase 1 de nuestro abrigo.

En la tercera y última fase nos enfrentamos a un cambio radical tanto estilística como conceptualmente. Se abandonan las pequeñas superficies para buscar amplios espacios en la roca donde plasmar las pinturas. Prácticamente se acaba con el uso del trazo grueso en la realización de las mismas para pasar a utilizar casi exclusivamente el fino, aplicado por medio de pequeños punzones de madera o hueso o finos pinceles de pluma de ave o pelo de animal, permitiendo al autor un mayor detallismo a la hora de dibujar los motivos sobre la piedra. Las pinturas conservan una tonalidad rojo vinosa mucho más intensa que los grafemas de fases anteriores, lo que hace más fácil su observación. El tamaño es sensiblemente menor que los motivos de fases precedentes, aunque no uniforme para todas las figuras. Se desea plasmar el concepto de jerarquización en función del tamaño de los grafemas. Así vemos como en el grupo IV los dos antropomorfos principales (fig. 8: 3-4), situados en la parte alta, superpuestos a dos zoomorfos de la fase 1 (fig. 8: 1-2), son de un tamaño

58 AcostA, P.: «El arte rupestre esquemático ibérico: problemas de cronología preliminares», Scripta Praehistorica, Homenaje a Fco. Jordá Cerdá, Salamanca, 1984, p. 31-61. 
notablemente mayor al resto de las figuras humanas de este panel. Esta jerarquía no se establece solamente en base al tamaño, sino tambien a la posición de los motivos. En la parte alta se localizan los personajes principales; más abajo, ocupando una zona intermedia, vemos un personaje aislado, similar en sus caracteres físicos al resto de los antropomorfos del panel, pero diferenciado por llevar un arco entre sus manos. El resto de las figuras ocupan la parte inferior de la escena. Queda claro que el autor de este panel juega con la superficie para buscar la composición de una escena, algo impensable en las fases precedentes. Además, nuestro pintor no concibe la escena con grafemas hieráticos, trata de dar vida a sus figuras, busca la lateralidad (casi constante en el arte levantino) y desea imprimir movimiento utilizando para ello diversos recursos técnicos como el flexionar las piernas y colocarlas a distinto nivel, la delantera más alta que la trasera.

Si en la primera fase la figura humana y animal priman por igual (los porcentajes de representaciones humanas y animales son similares, cuadro 1), ahora, en esta tercera, es la figura humana la que domina claramente sobre los motivos animalísticos (un $17,95 \%$ de antropomorfos frente al $5,13 \%$ de zoomorfos, cuadro 3 ).

Es el hombre el dominador de una sociedad fuertemente jerarquizada. Se busca el individualismo frente al resto de los personajes. Es por ello que se representan como elementos diferenciadores de los personajes, objetos de marcado valor etnográfico asociados a ellos (vestimentas, armamentos, tocados). De entre todos, hay que destacar fundamentalmente por sus implicaciones cronológicas el tocado que porta el motivo 8 del grupo $\mathrm{V}$ (fig. 9). Se trata de un tocado de cuernos, cuyos paralelos más próximos en pintura rupestre los hallamos en el abrigo 1 del Peñón del Pez (Peñalsordo) ${ }^{59}$ y en los tocados de cuernos que agrupa en su trabajo Pilar Acosta, localizados en el Abrigo Pequeño de Malas Cabras (Torremegía), en el Abrigo 10 de los Buitres (Peñalsordo) y en el Risco de San Blas (Alburquerque) ${ }^{60}$. Estas representaciones de figuras humanas tocadas con cascos de cuernos no son únicamente exclusivas de la pintura rupestre esquemática, una importante muestra aparece grabada sobre las numerosas estelas de guerrero encontradas en el suroeste peninsular, como la de Sao Martinho (Castelo Branco), Fuente de Cantos (Badajoz), Esparragosa de Lares (Badajoz), Capilla (Badajoz), Alamillo (Ciudad Real),

59 Martinez Perelló: "Un nuevo conjunto...", op. cit., p. 204-205, fig. 3.

so Acosta: La Pintura Rupestre..., op. cit., p. 148, fig. 44. 
Ecija (Sevilla) e incluso la estela de guerrero aparecida en la misma población de Magacela ${ }^{61}$.

Independientemente de la interpretación que ha sido atribuida a estas estelas, establecida casi siempre en base a su funcionalidad, bien como indicadoras de tumbas ${ }^{62} 0$ como marcador territorial ${ }^{63}$, podemos percibir en todas ellas elementos representativos de riqueza y prestigio personal vinculados claramente a las élites de sociedades fuertemente jerarquizadas. En ambos casos, ya en pintura rupestre, ya en estelas, nos enfrentamos a una misma sociedad cuyos preceptos elitistas, guerreros, personalistas e individualizadores, van a ser expresados por medio de un sistema de comunicación pictográfico accesible a todos aquellas personas o grupos humanos que tuvieran acceso a los abrigos donde se plasman las pinturas o a los lugares donde se implantaran las estelas.

Así pues, la cronología para el último período pictórico de Magacela correría paralela a la establecida para la vigencia de las estelas, centrada en el Bronce Final y cuya desaparición vendría motivada, según Eduardo Galán, por la reorientación general que sufre económica y socialmente la Península con la llegada de los elementos colonizadores en el Oriente y el Mediodía de la misma. A partir de estos momentos la implantación y la difusión de la escritura hará innecesario el tradicional medio de expresión y comunicación pictográfico que hasta entonces había supuesto la pintura rupestre esquemática la cual, poco a poco irá viendo reducido su uso, muy residual, a zonas marginales hasta perderse totalmente ya en periodo histórico, sin olvidar, no obstante, el arte rupestre que se desarrollará durante el medievo y la época moderna ${ }^{64}$; pero cuya concepción y funcionalidad nada tienen que ver ya con las motivaciones que impulsaron a las gentes desde el Neolítico hasta el Bronce Final a dejar sus mudos mensajes sobre las paredes de nuestros roquedos.

61 Galán Domingo, E.: Estelas, paisaje y territorio en el Bronce Final del suroeste de la península ibérica, Complutum extra 3, Madrid, 1993, p. 93-110, figs. 22 a 24.

62 Almagro BASCH, M.: Las estelas decoradas del suroeste peninsular, Bibliotheca Praehistorica Hispana, VIII, Madrid, 1966; Celestino PÉREZ, S: "Las estelas decoradas del suroeste peninsular", Cuadernos Emeritenses, 2, Merida, 1990, p. 45-62.

ô Galán Domingo, E: Estelas. paisaje y territorio en el Bronce final del suroeste de la Península Ibérica, Complutum extra 3, Madrid, 1993, p. 110.

64 Mateo SaURA, M.A.: "Arte rupestre histórico de la cueva del Esquilo», Revista de Arqueología, $\mathrm{n}^{\circ} 170$, Junio 1995, p. 913. 